\title{
The Psychotomimetic Effects of Intravenous Delta-9-Tetrahydrocannabinol in Healthy Individuals: Implications for Psychosis
}

\author{
Deepak Cyril D’Souza*,1,2,3, Edward Perry ${ }^{1,3}$, Lisa MacDougall',3, Yola Ammerman 1,3, Thomas Cooper,6, \\ Yu-te $\mathbf{W u}^{2,4}$, Gabriel Braley ${ }^{1,3}$, Ralitza Gueorguieva ${ }^{2,4}$ and John Harrison Krystal 1,2,3 \\ 'Schizophrenia Biological Research Center, VA Connecticut Healthcare System, West Haven, CT, USA; ${ }^{2}$ Abraham Ribicoff Research Facilities, \\ Connecticut Mental Health Center, New Haven, CT, USA; ${ }^{3}$ Department of Psychiatry, Yale University School of Medicine, New Haven, CT, USA \\ ${ }^{4}$ Division of Biostatistics, Department of Epidemiology and Public Health, Yale University, New Haven, CT, USA; ${ }^{5}$ Department of Psychiatry, \\ College of Physicians and Surgeons, Columbia University, New York, NY, USA; ${ }^{6}$ Nathan Kline Institute, Orangeburg, NY, USA
}

Recent advances in the understanding of brain cannabinoid receptor function have renewed interest in the association between cannabinoid compounds and psychosis. In a 3-day, double-blind, randomized, and counterbalanced study, the behavioral, cognitive, and endocrine effects of $0,2.5$, and $5 \mathrm{mg}$ intravenous delta-9-tetrahydrocannabinol ( $\Delta$-9-THC) were characterized in 22 healthy individuals, who had been exposed to cannabis but had never been diagnosed with a cannabis abuse disorder. Prospective safety data at I, 3, and 6 months poststudy was also collected. $\Delta$-9-THC (I) produced schizophrenia-like positive and negative symptoms; (2) altered perception; (3) increased anxiety; (4) produced euphoria; (5) disrupted immediate and delayed word recall, sparing recognition recall; (6) impaired performance on tests of distractibility, verbal fluency, and working memory (7) did not impair orientation; (8) increased plasma cortisol. These data indicate that $\Delta-9-\mathrm{THC}$ produces a broad range of transient symptoms, behaviors, and cognitive deficits in healthy individuals that resemble some aspects of endogenous psychoses. These data warrant further study of whether brain cannabinoid receptor function contributes to the pathophysiology of psychotic disorders.

Neuropsychopharmacology (2004) 29, I558-1572, advance online publication, 2 June 2004; doi: I 0. I038/sj.npp. 1300496

Keywords: delta-9-tetrahydrocannabinol; cannabinoids; psychosis; cognition; schizophrenia; cannabis

\section{INTRODUCTION}

'... acute psychotic reactions, generally lasting but a few hours, but occasionally as long as a week; the reaction seemed dose-related and its main features included paranoid ideation, illusions, hallucinations, delusions, depersonalization, confusion, restlessness and excitement.' in ' $\mathrm{Du}$ Haschisch et d l'alientation mentale' JJ Moreau de Tours (1845) (Moreau, 1973).

Until recently, the mechanism of action of cannabinoids remained an enigma. The cloning of brain cannabinoid receptors (CB-1 R), the identification of several endogenous ligands and second messenger systems, the development of selective CB-1 R antagonists, and other recent advances (reviewed in Freund et al, 2003; Pertwee, 1999b) have

\footnotetext{
*Correspondence: Dr DC D'Souza, Psychiatry Service, II6A, VA Connecticut Healthcare System, 950 Campbell Avenue, West Haven, CT 065 I6, USA, Tel: + I 203932 57| l ext. 2594, 257I, Fax: + I 203 937 4860, E-mail: deepak.dsouza@yale.edu

Received 2 February 2004; revised 9 April 2004; accepted 13 April 2004

Online publication: 22 April 2004 at http://www.acnp.org/citations/ Npp04220404044/default.pdf
}

rekindled interest in the association between cannabinoids and psychosis. Since the report of Moreau de Tours (1973), several studies (reviewed in Johns, 2001) suggest an association between psychosis and the use of cannabinoid compounds such as cannabis. There is a paucity of laboratory-based data directly evaluating the psychotomimetic effects of cannabinoid compounds and in particular those of delta-9-tetrahdrocannabinol ( $\Delta-9-\mathrm{THC})$, the principal active ingredient of cannabis.

The effects of cannabis are a composite of several (up to 80) cannabinoid compounds that may have effects that are synergistic with or antagonistic to $\Delta-9$-THC effects (Hollister, 1988). The principal aim of this study was to characterize the dose-related psychotomimetic effects of $\Delta$-9-THC, the principal active ingredient of cannabis, in carefully screened healthy individuals under double-blind, placebo-controlled laboratory conditions, using standardized behavioral and cognitive assessments.

\section{MATERIALS AND METHODS}

The study was conducted at the Neurobiological Studies Unit (VA Connecticut Healthcare System, West Haven, CT) 
with the approval of the Institutional Review Boards at VA Connecticut and Yale University, and the Protocol Review Committee of the Department of Psychiatry, Yale University.

Subjects were recruited from the community by advertisements and were paid for their participation in the study. Subjects were informed about the potential for psychosis, anxiety, and panic. After obtaining informed consent, subjects underwent a structured psychiatric interview for DSM-IIIR (Spitzer et al, 1990) and were carefully screened for any DSM-IV Axis I or Axis II lifetime psychiatric or substance abuse disorder (excluding nicotine) and family history of major Axis I disorder. The history provided by subjects was confirmed by a telephone interview conducted with an individual (spouse or family member) identified by the subject prior to screening. In order to avoid exposing cannabis-naïve individuals to a potentially addictive substance, only subjects who had been exposed to cannabis but did not meet lifetime criteria for a cannabis use disorder were included. Past month cannabis use was quantified using a time-line-follow-back approach. Finally, subjects underwent a general physical and neurologic examination, EKG, and laboratory tests (serum electrolytes, liver function tests, complete blood count with differential and urine toxicology). Subjects were instructed to refrain from caffeinated beverages, alcohol, and illicit drugs from 2 weeks prior to testing until study completion. Urine toxicology was conducted on the morning of each test day to rule out recent illicit drug use.

Subjects completed three test days during which they received 5 or $2.5 \mathrm{mg}$ of $\Delta-9$-THC, the principal active ingredient of cannabis, or vehicle (ethanol) by intravenous route in a randomized, counterbalanced order under double-blind conditions. Test days were separated by at least 1 week ( $>3$ times the elimination half-life of $\Delta-9$ THC) to minimize carryover effects (Wall et al, 1976). Two doses of $\Delta$-9-THC were chosen to examine dose-response relationships and were based on previous studies with $\Delta-9$ THC demonstrating feasibility and safety (Agurell et al, 1986; Volkow et al, 1991, 1996). The intravenous route of administration was chosen to reduce inter and intraindividual variability in plasma $\Delta$-9-THC levels with the inhaled route (Azorlosa et al, 1992) and to mimic the time course of plasma $\Delta-9-$ THC levels associated with the clinical 'high' (Agurell et al, 1986; Lindgren et al, 1981; Ohlsson et al, 1980a). Most studies with $\Delta$-9-THC employ an oral or inhalation (smoking) route of administration. Oral administration delays the onset of effects by $30-120 \mathrm{~min}$, produces lower peak plasma levels, and prolongs the action of the $\Delta$ 9-THC compared to the inhaled or intravenous route (Lemberger et al, 1971; Ohlsson et al, 1980b). The intravenous and smoked routes share similar pharmaco kinetic profiles. The dosing paradigm was designed to achieve peak $\Delta$-9-THC plasma levels comparable to those achieved by smoking standard cigarettes containing $1-3.5 \%$ $\Delta$-9-THC (16-34 mg).

$\Delta-9$-THC of $99.6 \%$ purity was provided by the NORAC Company, USA. $\Delta-9$-THC was dissolved in $95 \%$ ethanol (Agurell et al, 1986) to yield a concentration of $2 \mathrm{mg} / \mathrm{ml}$ stock solution, which was then passed through a $0.22 \mu \mathrm{m}$ polymer filter, subjected to sterility and pyrogenicity testing, and assayed by gas chromatography mass spectro- metry to confirm its concentration and stored at $-20^{\circ} \mathrm{C}$ for future use. For the control condition, an equivalent volume ( $\cong 2 \mathrm{ml}$ ) of ethanol (vehicle) was used, which would amount to a concentration of $0.0004 \%$ in an adult with average blood volume (4-51). Postinjection blood sampling at multiple time points failed to detect ethanol in a subsample of subjects. Subjects fasted overnight and reported to the test facility around 0800, where they were provided a standard breakfast. After obtaining two intravenous accesses at $-90 \mathrm{~min}$ and baseline assessments at $-60 \mathrm{~min}$, subjects were administered $\Delta-9$-THC intravenously over a 2 -min period into a rapidly flowing saline infusion. Subjects were attended to by a research psychiatrist, a research nurse, and a research coordinator. Clear 'stopping rules' were determined a priori and rescue medication (lorazepam) was available if necessary.

At the end of the last test day an exit interview was conducted to determine if subjects had been adequately informed prior to study participation and for feedback about the study procedures. The study was amended to include prospective measures addressing safety. Subjects were recontacted at 1,3,6 months poststudy and asked to estimate their desire for cannabis, whether their cannabis use had changed, and whether they had noted any new medical or psychiatric problems.

\section{Outcome Measures}

Behavioral ratings were conducted at the $-60,+10,+80$, +200 min timepoints (timepoint zero denotes the beginning of the $\Delta-9$-THC infusion). Since the peak intensity of $\Delta$-9-THC effects were expected to occur between +10 and +80 timepoints and were expected to disrupt a subject's capacity to describe subjective effects, behavioral ratings were readministered $140 \mathrm{~min}$ after $\Delta$-9-THC administration to capture $\Delta-9$-THC effects retrospectively. Positive, negative, and general symptoms were assessed using the PANSS positive, negative, and general symptoms subscales of the Positive and Negative Symptom Scale (PANSS) (Kay et al, 1989). Perceptual alterations were measured using the Clinician Administered Dissociative Symptoms Scale (CADSS) (Bremner et al, 1998), a scale consisting of 19 self-report items and eight clinician-rated items $(0=$ not at all, $4=$ extremely) that has been shown to be sensitive to the effects of other psychoactive drugs including ketamine (Krystal et al, 1994). Feeling states associated with cannabis intoxication were measured using five self-reported items of a visual analog scale items ('high', 'calm and relaxed', 'tired', 'anxious', 'panic') associated with cannabis effects (Haertzen, 1965, 1966). Subjects were asked to score the perceived intensity of these feeling states at that moment on a $100 \mathrm{~mm}$ line $(0=$ not at all, $100=$ extremely $)$.

At $30 \mathrm{~min}$ after receiving $\Delta-9$-THC a cognitive test battery was administered. Learning and recall were measured using the Hopkins Verbal Learning Test (HVLT) (Brandt et al, 1992; Bylsma et al, 1991). The test consists of three consecutive trials of immediate free recall of a 12 -item, semantically categorized list, followed $30 \mathrm{~min}$ later by testing of delayed free recall, cued recall, and recognition recall. Different but equivalent versions of the test were administered on the 3 test days. Vigilance and distractibility to visual stimuli were measured using a continuous 
performance task (Gordon, 1986) in which subjects attended to numbers presented sequentially on a screen. The subject pushed a button to signal when a ' 1 ' was preceded by a ' 9 '. The distractibility task was identical to the vigilance task with the exception that numbers were presented sequentially in three contiguous columns. Subjects were instructed to attend to the middle column and ignore the outer two columns. The verbal fluency task requires subjects to generate as many words as possible beginning with a specified letter during a 1-min interval (Corkin et al, 1964). Equivalent versions of this task were administered on the 3 test days using letters equated for frequency in English (Borkowski et al, 1967). Working memory was assessed using a computerized working memory task for shapes analogous to the Delayed Match to Sample task (Belger et al, 1998) and is known to activate prefrontal and hippocampal regions. Each trial consisted of an 'easy' or 'difficult' block classified on the basis of the complexity of shapes. In each block, subjects were presented 20 different shapes for $1 \mathrm{~s}$ each at intervals of $1 \mathrm{~s}$ on a computer screen and five shapes were repeated. Subjects were instructed to respond by pressing the spacebar when they identified a shape previously shown in that block. In total, 12 different versions of this task were available such that none of the shape stimuli were repeated across the 3 days of testing.

Vital signs were recorded at $-60,+10,+50,+80$, $+140,+200$ timepoints. At the $-60,+10,+80$, and +140 timepoints, blood was sampled from the i.v. line opposite to the one used for administering study drug, for prolactin and cortisol to provide a behaviorally independent measure of cannabinoid effects, and for levels of $\Delta-9-T H C$ and its primary inactive metabolite 11-nor-delta-9-tetrahydrocannabinol-9-COOH. However, for $\Delta-9-\mathrm{THC}$ and its main metabolite, only blood samples from the two active THC conditions were assayed. Immediately after collection, blood samples were put on ice, centrifuged, and the extracted plasma was alliquoted into vials for storage at $-70^{\circ} \mathrm{C}$ until time of the assay. Prolactin and cortisol assays were run in duplicate pairs using radioimmunoassay kits to determine prolactin (Serono Diagnostics, Inc.) and cortisol (Baxter Travenol Diagnostics, Inc.) levels. $\Delta-9$-THC and 11nor-delta-9-tetrahydrocannabinol-9-COOH were measured by GC/MS according to a method by Shaw et al (1991). Assays have intra- and interassay RSD\% of $<10 \%$ at $1 \mathrm{ng} / \mathrm{ml}$ with $0.5 \mathrm{ng} / \mathrm{ml}$ as the lower limit of detection.

\section{Statistical Analyses}

All analyses were performed in SAS Version 8.2. The change from baseline data was assessed for normality prior to analysis using normal probability plots and KolmogorovSmirnov test statistics. The absence of variance during the placebo $\Delta$-9-THC (vehicle) administration combined with highly skewed responses during the $\Delta-9$-THC conditions precludes the application of typical ANOVA's or mixed models and that ordinal or nonparametric approaches are needed. Since none of the outcomes conformed to normality due to floor effects, a nonparametric analysis for repeated measures data was used (Brunner et al, 2002). PANSS subscale scores, VAS scores, CADSS clinician, and CADSS subject ratings were analyzed using the \%LD_F2 SAS macro
(Brunner et al, 2002) with dose (placebo, low, high) and time (P10, P80, P200) as between-subject factors. One of the advantages of our statistical approach is that it uses all available data on each subject including dropouts. THC analyses were performed in the same way restricting the dose levels to low and high. The dose by time interaction was tested first and relative effects plots were used to interpret significant interactions. Hopkins, working memory, verbal fluency, measures of distractibility and vigilance (CPT), and retrospective behavioral data were analyzed using the \%LD_F1 macro. Hopkins immediate recall was analyzed using \%LD_F2 with only dose as a between-subject factor. Relative effect plots were also used to interpret significant dose effects. The overall alpha level for each hypothesis was fixed at 0.05 level. Bonferroni correction was applied within but not across hypothesis. Thus, for the two subscales of the PANSS (positive symptoms and negative symptoms), a cutoff alpha level of $0.05 / 2=0.025$ was used to declare effects significant for PANSS positive and for PANSS negative symptoms.

\section{RESULTS}

A total of 38 healthy subjects were initially screened of whom eight were found ineligible and eight never initiated the study. In all, 22 subjects initiated at least one test day (Table 1) with three and four subjects dropping out after completing 1 and 2 test days, respectively. Cannabis use histories are reported in Table 2 . None of the subjects had used cannabis for at least a week prior to testing and this was confirmed by urine toxicology. Data are reported either in figures or tables (means \pm SEM), while statistical analyses are reported in the text. For parsimony only those retrospective data that conflict with data collected at other timepoints $(+10$ or +80$)$ are reported in the text.

\section{Behavioral Measures}

Positive symptoms (PANSS). $\triangle$-9-THC transiently increased scores of the PANSS positive symptoms subscale (dose $\quad\left(\chi_{1,87}^{2}=20.2, \quad p<0.0001\right) ; \quad$ time $\quad\left(\chi_{1,99}^{2}=20.95\right.$, $p<0.0001) ; \quad$ dose $\times$ time $\left.\quad\left(\chi_{3,27}^{2}=8.30, \quad p=0.0001\right)\right)$ (Figure 1). The increases in positive symptoms induced by $\Delta$-9-THC peaked $10 \mathrm{~min}$ after drug administration, were modest and returned to baseline levels by the last timepoint. The quality of symptoms showed similarity to the positive symptoms reported by schizophrenia patients (Table 3) with some subjects losing insight momentarily.

Negative symptoms (PANSS). $\Delta$-9-THC transiently increased scores of the PANSS negative symptoms subscale (dose $\quad\left(\chi_{1,92}^{2}=19.1, \quad p<0.0001\right), \quad$ time $\quad\left(\chi_{1,54}^{2}=19.45\right.$, $p<0.0001)$; dose by time $\left.\left(\chi_{3,13}^{2}=7.27, \quad p=0.0005\right)\right)$ (Figure 1). Subjects were rated as being less spontaneous, internally preoccupied, and displaying blunted affect.

Perceptual alterations (CADSS). $\Delta$-9-THC transiently increased perceptual alterations as measured by the CADSS clinician-rated subscale (dose $\left(\chi_{1.97}^{2}=12.58, p=0.0000\right)$; time $\left(\chi_{1.84}^{2}=27.27, p=0.0000\right)$; dose by time $\left(\chi_{3.18}^{2}=9.09\right.$, $p=0.0000))$. Subjects were rated as being 'spaced out,' 
Table I Demographic Information

\begin{tabular}{|c|c|c|}
\hline & $n$ & Mean (SD) \\
\hline \multirow[t]{3}{*}{ Age $(S D)$ years } & All $(n=22)$ & $29(11.6)$ \\
\hline & Males $(n=14)$ & $30.4( \pm 11.8)$ \\
\hline & Females $(n=8)$ & $26.8( \pm 11.6)$ \\
\hline \multirow[t]{3}{*}{ Education (SD) years } & All & $16.3(1.9)$ \\
\hline & Males & $16.4( \pm 2)$ \\
\hline & Females & $16.1( \pm 1.9)$ \\
\hline \multirow[t]{2}{*}{ Handedness } & Right & 18 \\
\hline & Left & 4 \\
\hline \multirow[t]{3}{*}{ Race } & Caucasian & 15 \\
\hline & Indian & । \\
\hline & African American & 6 \\
\hline \multirow[t]{3}{*}{ Weight } & All & $174.7( \pm 46.4)$ \\
\hline & Males $(n=14)$ & |84.| $( \pm 40.2)$ \\
\hline & Females $(n=8)$ & $|58|.( \pm 54.3)$ \\
\hline
\end{tabular}

Table 2 Cannabis Use History

\begin{tabular}{ll}
\hline \# of exposures & n \\
\hline Estimated lifetime cannabis exposures & 7 \\
Less than 5 times & 0 \\
$5-10$ times & 3 \\
$11-20$ times & 2 \\
$21-50$ times & 4 \\
$51-100$ times & 6 \\
$>100$ times &
\end{tabular}

Time

Last exposure to cannabis

$$
\begin{aligned}
& \text { Past week } \\
& \text { I week-I month } \\
& \text { I-6 months } \\
& 6 \text { months-I year } \\
& \text { I-5 years } \\
& 5-10 \text { years } \\
& >10 \text { years }
\end{aligned}
$$

seeming separated or detached from the test environment, had said or done something bizarre or needed redirection. $\Delta$-9-THC also transiently increased perceptual alterations as measured by the CADSS subject-rated subscale (dose $\left(\chi_{1.69}^{2}=21.006, p=0.0000\right)$; time $\left(\chi_{1.86}^{2}=44.11, p=0.0000\right)$; dose by time $\left(\chi_{2.78}^{2}=7.38, p=0.0001\right)$ ) (Figure 2 ). Subjects reported having distorted time perception, external perception, feelings of unreality, and altered body perception.
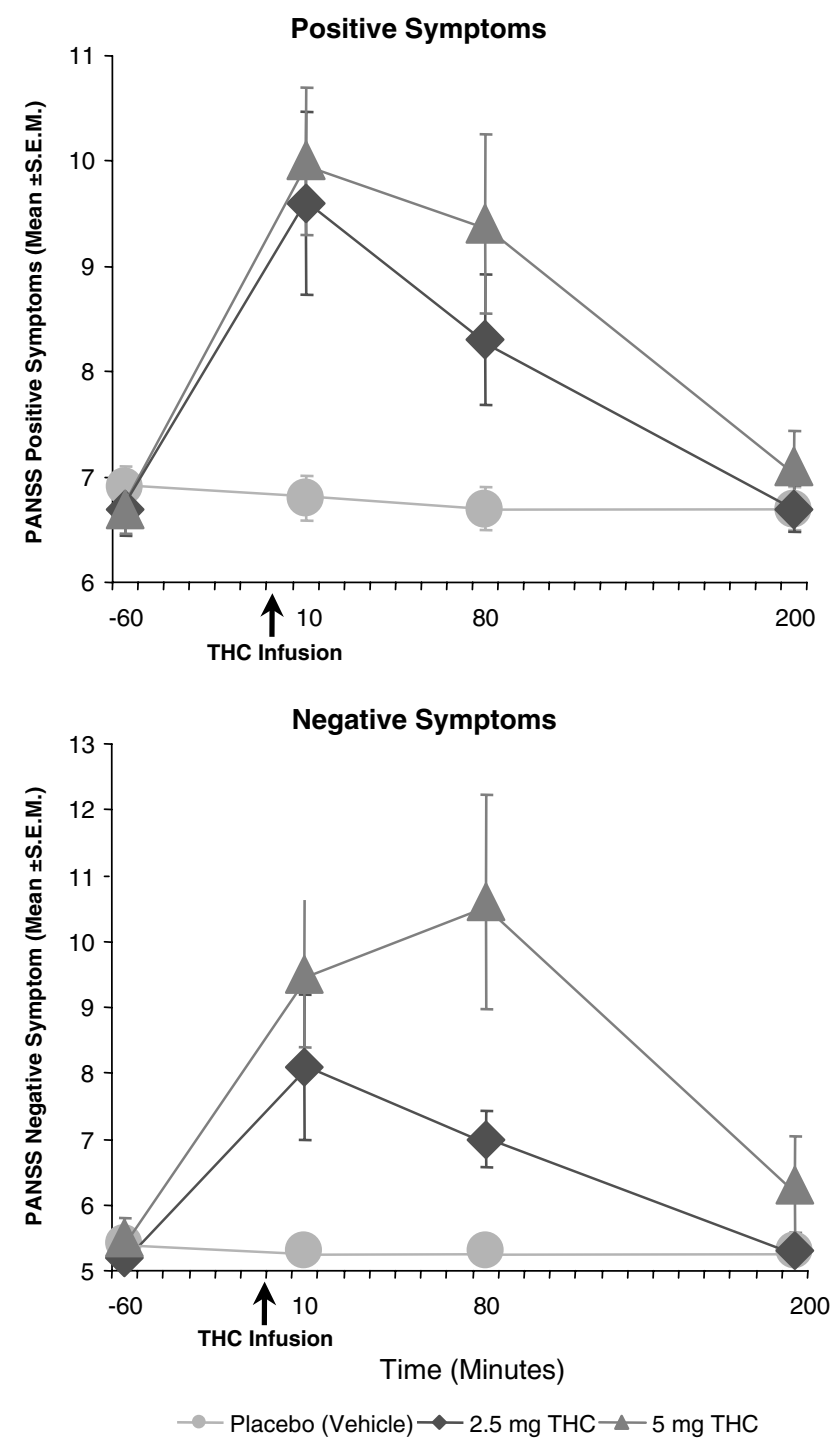

Figure I Effects of $\Delta-9-T H C$ on the seven-item positive (left panel) and six-item negative (right panel) symptom subscales of the Positive and Negative Syndrome Scale (PANSS). The PANSS is used to measure the symptoms associated with schizophrenia. Scores for each item range from 0 (absent) to 7 (extremely). The ranges of scores on the positive and negative subscales are 0-49 and 0-42, respectively.

General symptoms (PANSS). $\Delta$-9-THC transiently increased scores of the PANSS general symptoms subscale (dose $\quad\left(\chi_{1,76}^{2}=3.3, \quad p=0.043\right), \quad$ time $\quad\left(\chi_{1,63}^{2}=37.51\right.$, $p \& 1 t ; 0.0001)$, and dose $\times$ time $\left.\left(\chi_{3,32}^{2}=5.15, p=0.00095\right)\right)$ that includes items for somatic concern, guilt feelings, tension, uncooperativeness, unusual thought content, poor attention, and preoccupation.

\section{Feeling States}

'High' (VAS). $\Delta$-9-THC transiently increased VAS scores of 'high'(dose: $\left(\chi_{1.38}^{2}=31.56, p=0.0000\right)$; time $\left(\chi_{1.79}^{2}=22.32\right.$, $p=0.0000)$; dose by time $\left.\left(\chi_{2.02}^{2}=4.5, p=0.0108\right)\right)$ (Figure 3$)$.

'Anxious', 'calm and relaxed,' and 'panic' (VAS). $\Delta-9-\mathrm{THC}$ transiently increased VAS scores of 'anxious' (dose $\left(\chi_{1.88}^{2}=11.44, p=0.00002\right)$; time $\left(\chi_{1.27}^{2}=22.71, p=0.0000\right)$; 
Table 3 Subject Quotes

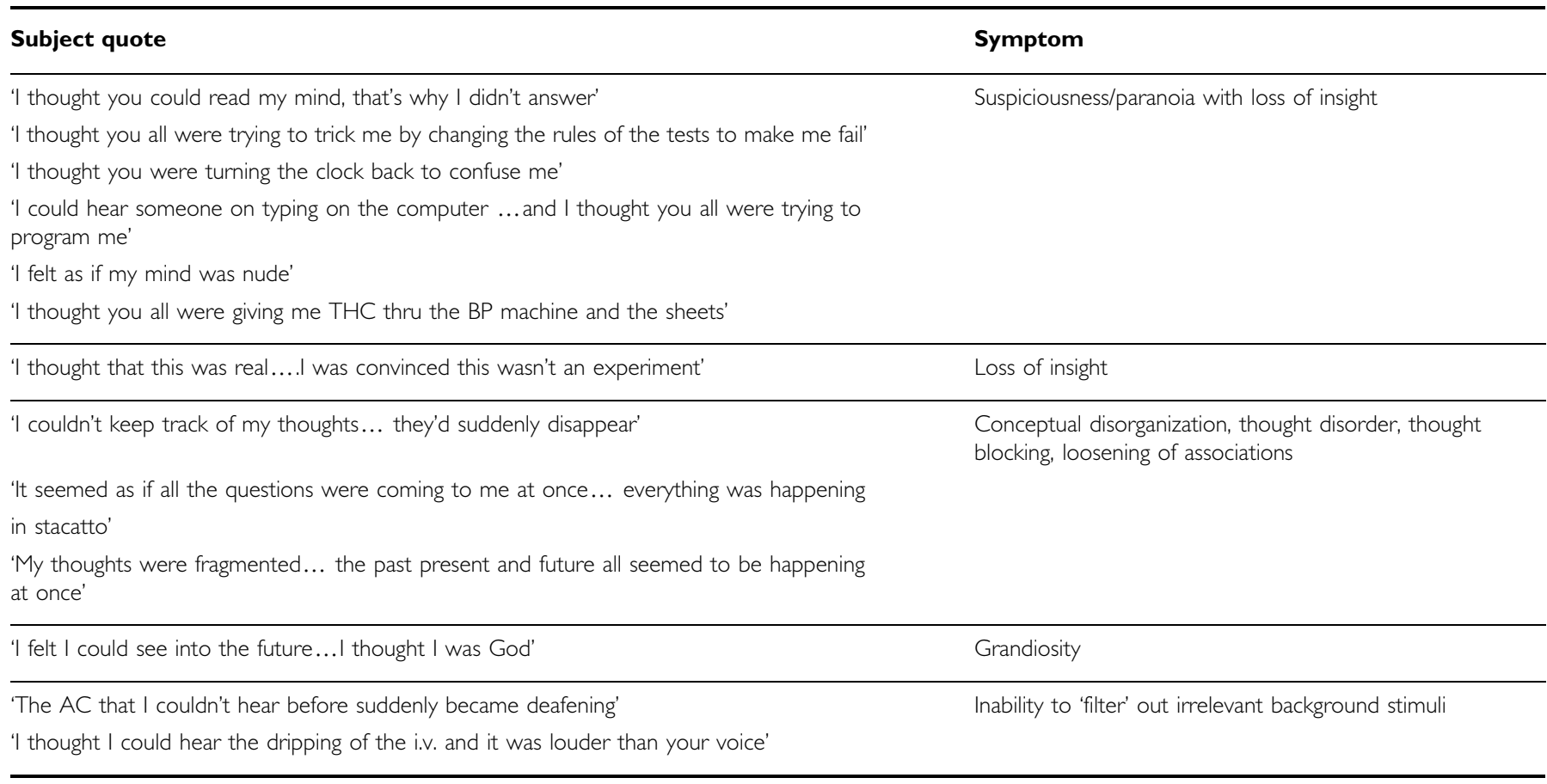

dose by time $\left.\left(\chi_{2.78}^{2}=3.58, p=0.0157\right)\right)$. Consistent with an increase in anxiety, $\Delta-9$-THC decreased VAS scores of 'calm and relaxed' (dose $\left(\chi_{2.00}^{2}=1.66, \quad p=0.1899\right)$; time $\left(\chi_{1.63}^{2}=8.73, \quad p=0.00049\right) ;$ dose by time $\left(\chi_{3.37}^{2}=2.61\right.$, $p=0.042))$. However, $\Delta-9-$ THC effects on VAS 'panic' scores were not statistically significant (dose $\left(\chi_{1.63}^{2}=0.72\right.$, $p=0.4612)$; time $\left(\chi_{1.59}^{2}=8.96, p=0.00045\right)$; dose by time $\left.\left(\chi_{3.32}^{2}=1.57, p=0.1884\right)\right)$.

'Tired'(VAS). $\Delta$-9-THC effects on VAS 'tired' scores in analysis of primary timepoint data were significant for dose $\left(\chi_{1.97}^{2}=11.53, p=0.00001\right)$ but not time $\left(\chi_{1.51}^{2}=0.755\right.$, $p=0.435)$ or the dose $\times$ time interaction $\left(\chi_{3.21}^{2}=0.611\right.$, $p=0.62)$. Analysis of the retrospective timepoint data revealed a significant dose effect $\left(\chi_{1.85}^{2}=9.23, p=0.0001\right)$ of $\triangle-9-\mathrm{THC}$ on increasing VAS 'tired' scores.

\section{Neuropsychological Measures}

Immediate recall, delayed recall and learning (Hopkins Verbal Learning Test) (Figure 4). $\Delta$-9-THC significantly impaired immediate recall $\left(\left(\right.\right.$ dose $\quad\left(\chi_{1.31}^{2}=12.32\right.$, $p=0.00011)$; trial $\left.\left(\chi_{1.73}^{2}=64.51, p=0.0000\right)\right)$ in a dosedependent manner across all three trials of immediate recall. However, its effects on learning were not statistically significant (dose by trial: $\chi_{3.28}^{2}=1.58, p=0.1875$ ). $\Delta$-9-THC impaired delayed $(+30 \mathrm{~min})$ free recall (dose: $\chi_{1.69}^{2}=6.55$, $p=0.00266)$ and delayed cued recall (dose: $\left(\chi_{1.97}^{2}=4.06\right.$, $p=0.0177)$ in a significant, dose-dependent manner. However, its effect on delayed recognition recall showed a trend towards significance (dose: $\left(\chi_{1.98}^{2}=2.65, p=0.07\right)$. Finally, $\Delta$-9-THC increased the number of false positives (dose: $\chi_{1.76}^{2}=2.43, p=0.095$ ) and intrusions (dose: $\chi_{1.88}^{2}=2.85$, $p=0.06)$ with a trend towards significance.
Distractibility and vigilance. $\Delta-9$-THC had no effect on omission (dose: $\chi_{1.99}^{2}=0.46, p=0.62$ ) or commission (dose: $\left.\chi_{1.75}^{2}=0.68, p=0.487\right)$ errors in the vigilance task. $\Delta-9-\mathrm{THC}$ effects on latency trended towards significance $\left(\chi_{1.95}^{2}=2.69\right.$, $p=0.068) . \Delta$-9-THC had significant dose effects on omission errors $\left(\chi_{1.73}^{2}=4.70, \quad p=0.0126\right)$ and latency $\left(\chi_{1.94}^{2}=3.06, p=0.048\right)$ but not commission errors (dose: $\left.\chi_{1.89}^{2}=0.81, p=0.44\right)$ in the distractibility task (Table 4 ).

Verbal fluency. $\Delta-9-$ THC did not have any significant dose effects on the number of words generated in 1 min (dose: $\left.\chi_{1.90}^{2}=0.977, p=0.373\right)$, but trended towards increasing the number of perseverations (dose: $\chi_{1.94}^{2}=2.61, p=0.075$ ) (Table 4).

Working memory. $\Delta$-9-THC significantly reduced the number of correct responses in the easy subtask (dose: $\chi_{1.91}^{2}=4.22, p=0.016$ ) without effecting reaction time (dose $\chi_{1.75}^{2}=0.174, p=0.8$ ). However, $\Delta-9$-THC did not reduce the number of correct responses in the hard subtask (dose $\left.\chi_{1.99}^{2}=1.29, p=0.275\right)$, but trended towards increasing reaction time (dose $\chi_{1.87}^{2}=2.47, p=0.088$ ) (Table 4 ).

\section{Neurochemical Effects}

Cortisol and prolactin. $\Delta-9-\mathrm{THC}$ had no significant effects on serum prolactin levels (dose (NS); time $\left(\chi_{1.84}^{2}=20.4\right.$, $p=0.0000$ ); dose by time (NS)) (Figure 5), but significantly increased serum cortisol levels (dose $\left(\chi_{1.97}^{2}=12.44\right.$, $p=0.0000)$; time $\left(\chi_{1.81}^{2}=4.01, p=0.02164\right)$, dose by time $\left.\left(\chi_{2.52}^{2}=5.3, p=0.00236\right)\right)$.

4-9-THC and 11-nor-delta-9-tetrahydrocannabinol-9$\mathrm{COOH}$ levels. Blood samples were analyzed only on the 

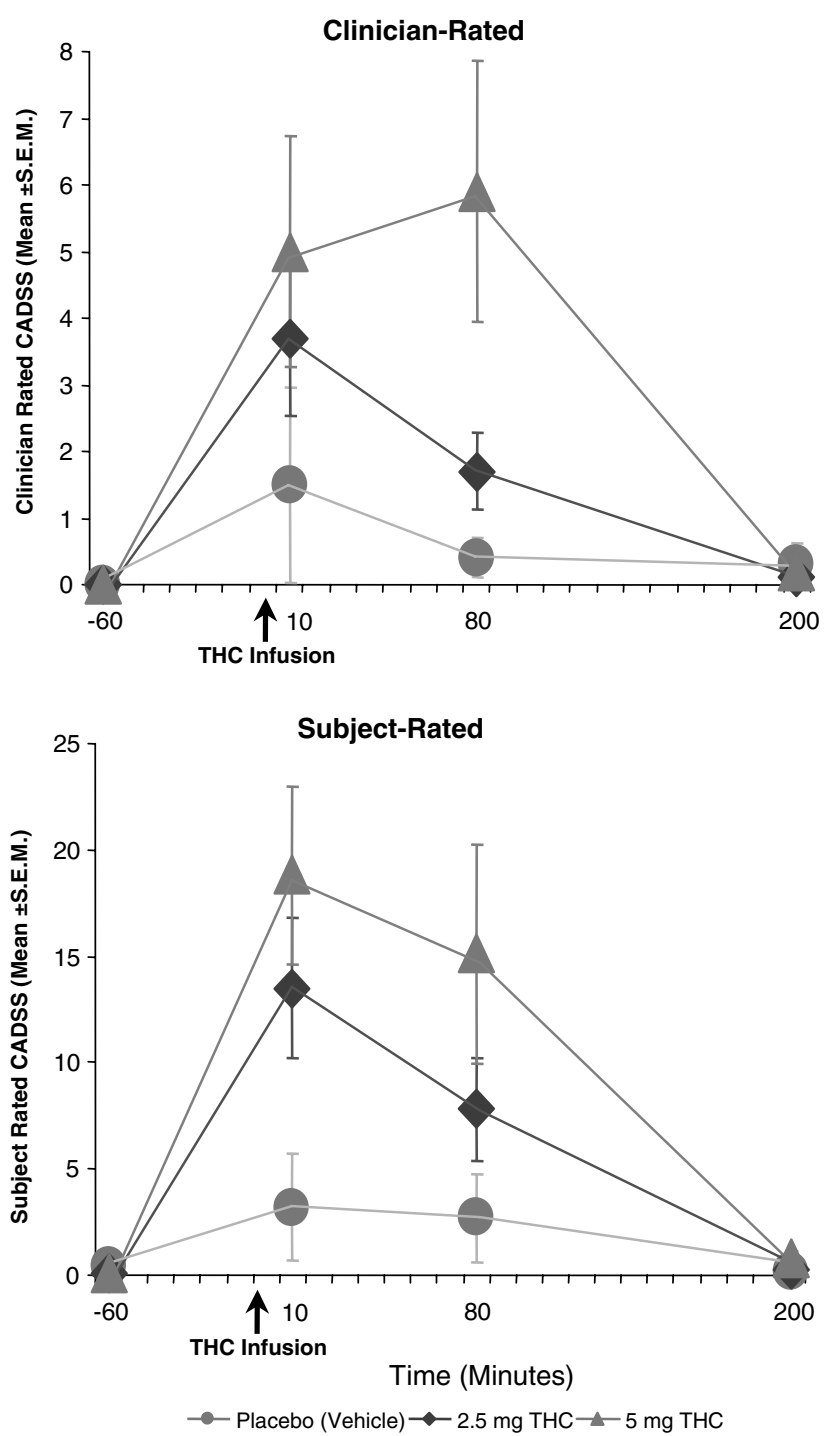

Figure 2 Effects of $\Delta-9-T H C$ on the eight-item clinician-rated (left panel) and 19-item subject-rated (right panel) subscales of the Clinician Administered Dissociative Symptoms Scale CADSS). The CADSS is used to measure perceptual alterations. Scores for each item range from 0 (absent) to 4 (extremely). The ranges of scores on the clinician- and subject-rated subscales are $0-32$ and $0-76$, respectively.

two active test days. Plasma $\Delta$-9-THC levels were highest at the $+10 \mathrm{~min}$ timepoint $(2.5 \mathrm{mg}$ dose $=82 \mathrm{ng} / \mathrm{dl}( \pm 87.4)$; $5 \mathrm{mg}$ dose $=119.2 \mathrm{ng} / \mathrm{dl}( \pm 166.5))$, lower at the +80 timepoint and fell considerably by the +200 timepoint. However, differences between the two doses were not statistically significant (dose $\left(\chi_{1}^{2}=2.32, p=0.1278\right)$; time $\left(\chi_{1.43}^{2}=69.36, p=0.0000\right)$; dose by time $\left(\chi_{1.63}^{2}=1.86\right.$, $p=0.164)$ ). This is probably as a result of significant variability in the plasma $\Delta-9$-THC concentrations observed. 11-nor-delta-9-tetrahydrocannabinol-9- $\mathrm{COOH}$ levels were highest at the $+10 \mathrm{~min}$ timepoint $(2.5 \mathrm{mg}$ dose $=43.8 \mathrm{ng} /$ $\mathrm{dl}( \pm 26.1) ; 5 \mathrm{mg}$ dose $=81.9 \mathrm{ng} / \mathrm{dl}( \pm 47))$ were lower at the +80 timepoint $(2.5 \mathrm{mg}$ dose $=28.6 \mathrm{ng} / \mathrm{dl} \quad( \pm 19.3) ; 5 \mathrm{mg}$ dose $=49.5 \mathrm{ng} / \mathrm{dl}( \pm 30.4))$ and remained detectable at the +200 timepoint. Differences between the two doses were statistically significant (dose $\left(\chi_{1}^{2}=4.08, p=0.043\right)$; time $\left(\chi_{1.47}^{2}=60.43, p=0.0000\right)$; dose by time $\left(\chi_{1.57}^{2}=0.875\right.$, $p=0.394)$ ). Since plasma $\Delta-9$-THC levels are out of phase (hysteresis) with behavioral changes (Cocchetto et al, 1981; Cone and Huestis, 1993; Huestis et al, 1992), no attempt was made to correlate plasma levels to behavioral, cognitive, or endocrine measures.

\section{Safety Data}

No serious adverse events (death, hospitalization, emergency room visit) occurred during the study. The reasons for dropouts included acute paranoia $(n=1)$, panic $(n=1)$, hypotension $(n=2)$, difficulty with venous access $(n=1)$, withdrawal of consent due to dislike of THC effects $(n=3)$, and scheduling difficulties or other non-study issues $(n=1)$. The one subject who experienced a significant, acute paranoid reaction associated with significant distress after receiving $5 \mathrm{mg}$ THC was administered $2 \mathrm{mg}$ lorazepam with good effect. Exit interviews conducted in a subsample of subjects revealed that subjects felt they had been adequately informed about the risks of the study during the consent process. Follow-up assessments $(1,3$ and 6 months) failed to show the emergence of new psychiatric symptoms or any change on several measures of cannabis use (Table 5).

\section{DISCUSSION}

The principal finding of the study is that $\Delta$-9-THC produced transient effects in healthy individuals including positive symptoms, negative symptoms, perceptual alterations, euphoria, anxiety, and deficits in working memory, recall, and the executive control of attention without altering general orientation. The positive symptoms induced by $\Delta-9$-THC included suspiciousness, paranoid and grandiose delusions, conceptual disorganization, and illusions. It also produced depersonalization, derealization, distorted sensory perceptions, altered body perception, feelings of unreality and extreme slowing of time. $\Delta-9$-THC produced negative symptoms including blunted affect, reduced rapport, lack of spontaneity, psychomotor retardation, and emotional withdrawal.

While cannabis has been reported to impair several aspects of cognitive functioning in a dose-related manner, deficits in verbal recall appear to be the most consistent finding in laboratory studies (Belmore and Miller, 1980; Chait and Zacny, 1992; Curran et al, 2002; Hart et al, 2001; Heishman et al, 1997, 1990; Hooker and Jones, 1987; Marks and MacAvoy, 1989; Miller and Branconnier, 1983; Miller et al, 1977). Our data are consistent with these effects. $\Delta-9$ THC impaired verbal recall but not learning, suggesting that its effects are primarily on verbal working memory. While $\Delta$-9-THC disrupted delayed recall, these effects appeared to be largely as a consequence of a disruption in immediate recall. The observation that recognition recall was least disrupted, suggests that $\Delta$-9-THC impairs retrieval more than encoding.

In comparing the cognitive data from this study with more recent studies, several factors need to be considered including, but not limited to, the degree of current cannabis use (tolerance) and lifetime cannabis exposure of the study 
(Visual Analog Scale)
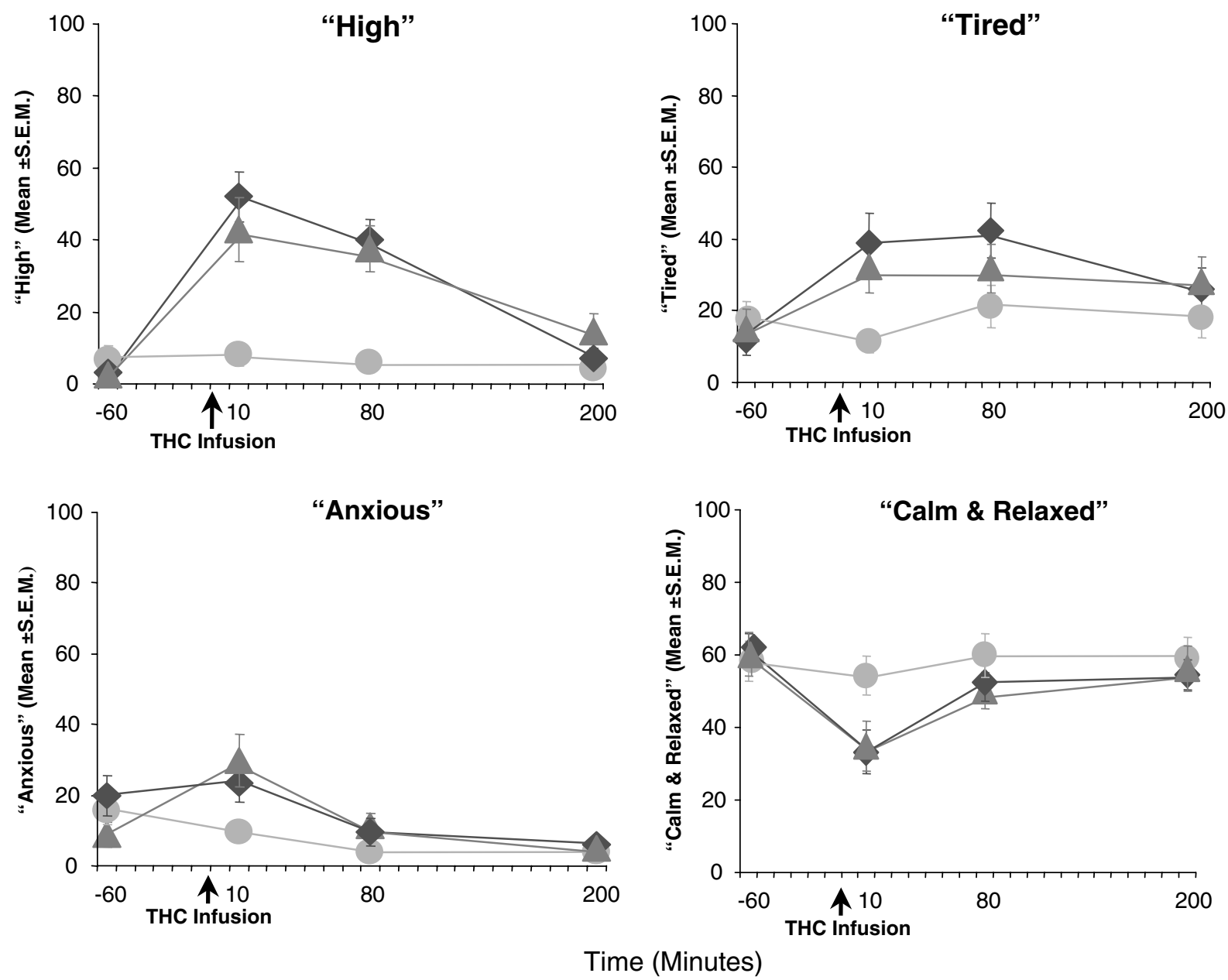

Time (Minutes)

- Placebo (Vehicle) $\longrightarrow 2.5 \mathrm{mg}$ THC $\longleftarrow 5 \mathrm{mg}$ THC

Figure 3 Effects of $\Delta-9-T H C$ on feeling states associated with the cannabis response. Each feeling state was measured with a visual analog scale $(0=$ not at all to $100=$ extremely).

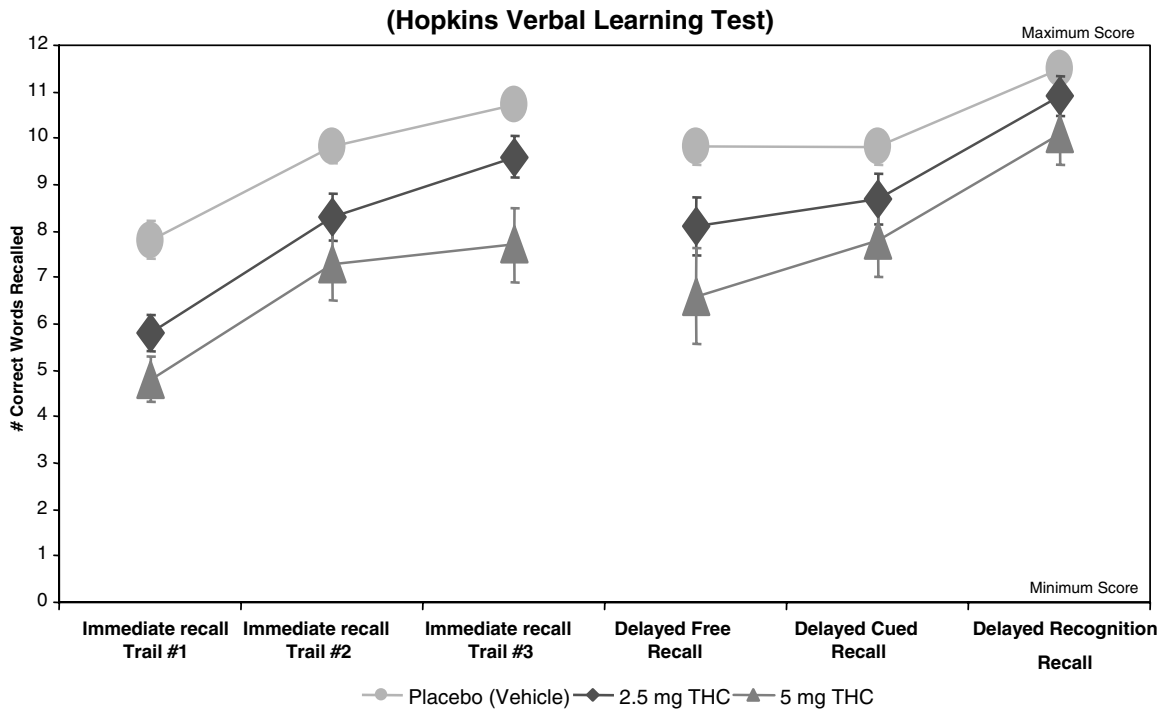

Figure 4 Effects of $\Delta-9-$ THC on learning, immediate free recall, delayed free recall, delayed cued and recognition recall measured by a I2-word learning task (Hopkins Verbal Learning Test). 
Table $4 \Delta$-9-THC Effects on Neuropsychological Test Performance

\begin{tabular}{|c|c|c|c|c|}
\hline Outcome measure & Placebo $\Delta-9-T H C$ & $2.5 \mathrm{mg} \Delta-9-\mathrm{THC}$ & $5 \mathrm{mg} \Delta-9-\mathrm{THC}$ & Dose effect \\
\hline \multicolumn{5}{|l|}{ Vigilance } \\
\hline$n$ & 19 & 19 & 15 & \\
\hline Omission errors & I.I $( \pm 2.1)$ & $0.9( \pm 1.3)$ & $2( \pm 4.9)$ & $\chi_{1.99}^{2}=0.46, p=0.62$ \\
\hline Commission errors & $0.4( \pm 0.7)$ & $0.4( \pm 0.6)$ & $0.7( \pm 1)$ & $\chi_{1.75}^{2}=0.68, p=0.487$ \\
\hline Latency & $42.4( \pm 7.4)$ & $44.1( \pm 8.4)$ & $45.6( \pm 8.3)$ & $\chi_{1.95}^{2}=2.69, p=0.068$ \\
\hline \multicolumn{5}{|l|}{ Distractibility } \\
\hline$n$ & 19 & 18 & 15 & \\
\hline Omission errors & $2.5( \pm 3.7)$ & $3.8( \pm 4.4)$ & $6.6( \pm 8.4)$ & $\chi_{1.73}^{2}=4.70, p=0.0126$ \\
\hline Commission errors & $0.9( \pm 2.3)$ & $1.3( \pm 2.4)$ & $5.7( \pm 17.1)$ & $\chi_{1.89}^{2}=0.81, p=0.44$ \\
\hline Latency & $41.7( \pm 6.2)$ & $44.8( \pm 6.7)$ & $48.2( \pm 14.3)$ & $\chi_{1.94}^{2}=3.06, p=0.048$ \\
\hline Perseverations & $0.4( \pm 0.8)$ & $0.1( \pm 0.3)$ & $0.4( \pm 0.5)$ & $\chi_{1.94}^{2}=2.61, p=0.075$ \\
\hline \multicolumn{5}{|l|}{ Working memory } \\
\hline$n$ & 17 & 18 & 16 & \\
\hline Easy task correct & $4.1( \pm 1.3)$ & $3.1( \pm 1.5)$ & $3.9( \pm 1.2)$ & $\chi_{1.91}^{2}=4.22, p=0.016$ \\
\hline Easy task reaction time & $887.6( \pm 242.8)$ & $908.8( \pm 240.3)$ & $954.4( \pm 273.5)$ & $\chi_{1.75}^{2}=0.174, p=0.811$ \\
\hline$n$ & 18 & 18 & 15 & \\
\hline Hard task correct & $3.5( \pm 1.2)$ & $2.8( \pm 1.4)$ & $2.9( \pm 1.9)$ & $\chi_{1.99}^{2}=1.29, p=0.275$ \\
\hline Hard task reaction time & $977.8( \pm 311.3)$ & $1077.3( \pm 266.9)$ & $953.6( \pm 209.3)$ & $\chi_{1.87}^{2}=2.47, p=0.088$ \\
\hline
\end{tabular}

sample, the dosing paradigm, the task characteristics and at what timepoint the tests were administered. In contrast to our study, Hart et al (2001) found minimal effects of $\Delta-9$ THC on cognitive test performance; however, the subjects were cannabis dependent and were smoking an average of four cannabis joints per day for several years.

Curran et al (2002) studied subjects who had similar cannabis use histories to our subjects. However, relative to our study, Curran et al (2002) used oral $\Delta$-9-THC which achieved much lower plasma levels, employed some different cognitive tasks, and administered those tasks at different timepoints in the $\Delta-9$-THC dose-response curve. The effects of $\Delta-9$-THC on immediate and delayed verbal recall are in agreement with the current study. However, whereas we found that $\Delta-9$-THC impaired performance on a computerized visual working memory for shapes, Curran et al (2002) did not find an effect on a relatively simpler task of working memory, the serial sevens task. Our data are consistent with an extensive animal literature showing a robust effect of cannabinoids on working memory (reviewed in Lichtman et al, 2002). When the rapid visual processing task of sustained attention was made more demanding in our study similar to the task of Curran (2002), $\Delta$-9-THC appeared to impair performance. Consistent with this, several subjects reported that after receiving $\Delta$-9-THC, irrelevant sounds and visual patterns that were previously in the background, for example, the sound of the airconditioner or the pattern of the curtains, came to the foreground and was perceived as distracting. This might reflect a disruptive effect of $\Delta-9$-THC on the 'filtering' of nonsalient information that has been observed in long-term cannabis users (Solowij et al, 1991).

$\Delta$-9-THC produced these effects in healthy individuals carefully screened for any obvious risk factors for psychosis, including any DSM-IV Axis I diagnosis in firstdegree relatives. The basis of why some subjects but not others experienced transient but significant psychotic symptoms is not clear, but is of considerable interest. Several large sample studies $(n=7000-500000)$ suggest that moderate (more than 20 times) lifetime exposure to cannabis is associated with a higher risk to develop schizophrenia later on (Andreasson et al, 1988; van Os et al, 2002; Zammit et al, 2002). Therefore, we examined the relationship between lifetime cannabis exposure (Table 2) and psychotomimetic effects of $\Delta-9$-THC in this study. The sample was divided into two groups based on whether subjects had been exposed to cannabis more or less than 20 times in their lifetime. The difference in peak change in PANSS positive symptom subscale scores between the $5 \mathrm{mg}$ $\Delta$-9-THC and placebo condition was the outcome used. The two groups were not significantly different $\left(t_{15}=0.44\right.$, $p=0.666)$ in their response to $\Delta$-9-THC effects on peak positive symptom scores. The lack of any obvious relationship between lifetime cannabis exposure (Table 2) and psychotomimetic response to $\Delta-9$-THC are in contrast large epidemiological studies. One possible explanation for this 

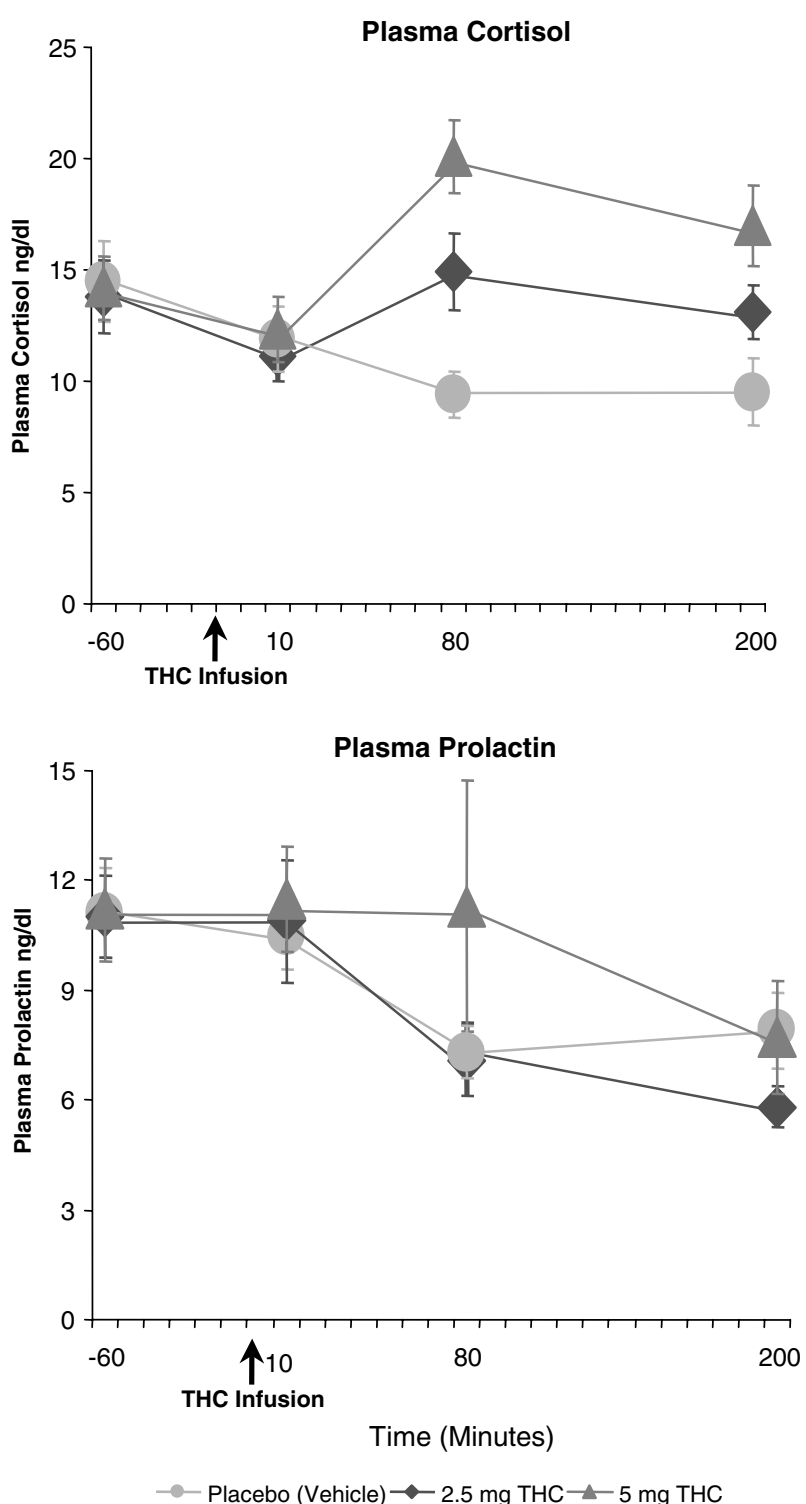

Figure 5 Effects of $\Delta-9-T H C$ on plasma prolactin and cortisol levels.

contrast is that the small sample in our study may not have allowed the detection of a relationship between lifetime cannabis exposure and the psychotomimetic response to $\Delta$ 9-THC.

The constellation of symptoms produced by $\Delta-9$-THC resembles several dimensions of endogenous psychotic disorders like schizophrenia. The findings of this study provide support for a cannabinoid 'model' psychosis (Beringer and Marx, 1932) just as dopaminergic (DA) stimulants (amphetamine), serotonergic agents (LSD and psylocibin), and glutamatergic antagonists (ketamine) have been studied as laboratory-based models of endogenous psychotic disorders (Adler et al, 1998; Angrist et al, 1974; Ellison, 1994; Krystal et al, 1994; Lieberman et al, 1987; Malhotra et al, 1996; Siomopoulos, 1975; Snyder, 1973; Vollenweider et al, 1998, 2000). In contrast to DA stimulants, $\Delta$-9-THC like ketamine produced positive, negative, and cognitive symptoms of psychosis.
The findings of this study add to a growing body of literature from pharmacological (Jones, 1971; Leweke et al, 2000, 1999b; McGuire et al, 1995), epidemiological (Andreasson et al, 1987, 1988, 1989; Arseneault et al, 2002; McGuire et al, 1995; Zammit et al, 2002), genetic (Ujike et al, 2002), neurochemical (Leweke et al, 1999a), and postmortem (Dean et al, 2001) approaches, suggesting that the consumption of cannabinoids (exogenous) and/or brain cannabinoid dysfunction (endogenous) may contribute to the pathophysiology of psychosis and/or schizophrenia (Emrich et al, 1997; Schneider et al, 1998). Clearly, further work is needed to test these hypotheses.

\section{The Mechanism of the Psychotic Symptoms Induced by} $\Delta$-9-THC

The psychotropic effects of $\Delta-9$-THC are mediated by partial agonist effects at $\mathrm{CB}-1$ receptors (CB-1R) where it has modest affinity $\left(K_{i}=35-80 \mathrm{nmol}\right)$ and low intrinsic activity (Compton et al, 1992; Gerard et al, 1991; Howlett et al, 2002; Matsuda et al, 1990). However, its hydroxy metabolite has higher affinity and potency. The primary effect of cannabinoids is the modulation of neurotransmitter release via activation of presynaptic CB-1Rs (reviewed in Belue et al, 1995; Freund et al, 2003; Pertwee, 1999a). CB1 Rs are distributed with high density in the cerebral cortex, particularly frontal regions, basal ganglia, hippocampus, anterior cingulate cortex, and cerebellum (Egertova and Elphick, 2000; Egertova et al, 1998; Elphick and Egertova, 2001; Glass et al, 1997; Herkenham et al, 1991, 1990), brain regions that are relevant to both the known effects of cannabinoids and also regions that have been implicated in the putative neural circuitry of psychosis.

The effect of CB-1R activation on increasing mesolimbic DA activity may provide one explanation for the positive psychotic symptoms induced by $\Delta-9-\mathrm{THC}$ (Chen et al, 1990b, 1991; French, 1997; French et al, 1997; Melis et al, 2000; Pistis et al, 2002; Tanda et al, 1997). CB-1R agonists induce cfos in the NAc (Miyamoto et al, 1996) and A10 DA neurons within the ventral tegmentum (Patel and Hillard, 2003), and these effects are blocked by DA D2 receptor antagonists (Miyamoto et al, 1996) and CB-1R antagonists (Patel and Hillard, 2003; Porcella et al, 1998).

In the hippocampus, $\mathrm{CB}-1 \mathrm{R}$ are located primarily on cholecystokinin containing GABAergic interneurons (Hajos et al, 2000; Katona et al, 2000, 1999a, 1999b; Tsou et al, 1999). These GABAergic interneurons are believed to orchestrate fast synchronous oscillations in the gamma range, a critical process in synchronizing pyramidal cell activity (Hajos et al, 2000; Hoffman and Lupica, 2000). Gamma oscillations are synchronized over long distances in the brain and are hypothesized to 'bind' together sensory perceptions and to play a role in cognition (reviewed in Wilson and Nicoll, 2002). Abnormalities in gamma band synchronization have been reported in schizophrenia (Spencer et al, 2003). Activation of these presynaptic CB1 Rs reduces GABA release by interneurons (Sullivan, 1999; Katona et al, 1999a), which in turn would disrupt the synchronization of pyramidal cell activity (Wilson and Nicoll, 2002; Hoffman and Lupica, 2000), thereby interfering with associative functions, disrupting normal gating mechanisms, and eventually inducing psychotic symptoms. 
Table 5 Prospective Follow-up of Safety

\begin{tabular}{lcccr}
\hline Visit \# & $\boldsymbol{n}$ & No change & Increased & Decreas \\
\hline Do you think your exposure to & THC in the laboratory & has changed your cannabis use? \\
I month & 10 & 8 & 0 & 2 \\
3 month & 12 & 8 & 0 & 4 \\
6 month & 12 & 10 & 0 & 2
\end{tabular}

$\begin{array}{lllll}\text { Visit \# } & \text { None at all Slightly less } \quad \text { About the usual more }\end{array}$

\begin{tabular}{|c|c|c|c|c|c|c|c|}
\hline \multicolumn{8}{|c|}{ Please estimate how intense your desire for cannabis has been since your last test day or questionnaire } \\
\hline I month & 10 & 5 & I & 3 & $I^{\mathrm{a}}$ & 0 & \\
\hline 3 month & 12 & 5 & 2 & 4 & $I^{\mathrm{a}}$ & 0 & \\
\hline 6 month & 12 & 7 & 2 & 3 & 0 & 0 & \\
\hline Visit \# & $\mathbf{N}$ & Not at all & I $\times /$ week & 2-3 × /week & 4-5 × / week & 6-8 × /week & $\geqslant 9 \times /$ week \\
\hline \multicolumn{8}{|c|}{ Since your last test day or questionnaire, how many times per week have you used cannabis? } \\
\hline I month & 10 & 6 & 2 & 1 & I & 0 & 0 \\
\hline 3 month & 12 & 7 & 2 & I & I & 1 & 0 \\
\hline 6 month & 12 & 9 & I & I & 0 & I & 0 \\
\hline Visit \# & $\mathbf{N}$ & $0-1$ & $2-3$ & 4-5 & $6-8$ & $\geqslant 9$ & \\
\hline
\end{tabular}

Since your last test day or questionnaire, please estimate your daily cannabis use (in dime bags)?

\begin{tabular}{|c|c|c|c|c|c|}
\hline I month & 10 & 12 & 0 & 0 & 0 \\
\hline 3 month & $11^{b}$ & 12 & I & 0 & 0 \\
\hline 6 month & $11^{b}$ & 12 & I & 0 & 0 \\
\hline
\end{tabular}

a This subject declared that his cannabis use had increased as a result of moving back to his home country where cannabis was more accessible to him, and the social and legal consequences to cannabis use were minimal.

${ }^{\mathrm{b}}$ One person did not answer this question.

The effects of CB-1R activation on hippocampal LTP and LTD may explain $\Delta$-9-THC's amnestic effects. CB-1R activation blocks LTP of CA1 region field potentials (Nowicky et al, 1987; Collins et al, 1994, 1995; Terranova et al, 1995; Misner and Sullivan, 1999) and CB-1 receptor knockout mice have been reported to show enhanced LTP (Bohme et al, 2000).

CB-1R activation also effects acetylcholine $(\mathrm{ACH})$ release in an inverted ' $U$ ' dose-response manner (Acquas et al, 2000, 2001; Gessa et al, 1998, 1997; Nava et al, 2001; Carta et al, 1998). Inhibition of acetylcholine release from cholinergic hippocampal neurons located in the septohippocampal pathway may provide another mechanism for the amnestic effects of cannabinoids.

$\mathrm{CB}-1 \mathrm{R}$ receptor activation stimulates mesoprefrontal DA transmission (Chen et al, 1990a; Diana et al, 1998; Jentsch et al, 1997; Pistis et al, 2001). Considering that supranormal stimulation of DA D1 receptors in the PFC has been shown to impair working memory, the negative effects of cannabinoids on working memory and other cognitive processes might be related to the activation of DA transmission in the PFC. Alternatively, cannabinoids, by inhibiting GABA release from GABAergic interneurons, may also suppress a mechanism by which DA controls PFC neuronal excitability. This might lead to nonspecific activation of the PFC, which in turn may disrupt normal signal processing and result in poor integration of transcortical inputs (Pistis et al, 2001). Cannabinoids have also been shown to influence glutamatergic synaptic transmission and plasticity in the PFC favoring LTD at the expense of LTP (Auclair et al, 2000).

Finally, animal studies have demonstrated that chronic exposure to cannabis in animals can induce behavioral sensitization to subsequent cannabinoid exposure (Cadoni et al, 2001; Rubino et al, 2001, 2003) and also to amphetamine (Gorriti et al, 1999; Lamarque et al, 2001; Miyamoto et al, 1995; Muschamp and Siviy, 2002). Sensitization has been implicated as a mechanism involved in psychosis (Laruelle, 2000; Duncan et al, 1999; Yui et al, 1999). It is tempting to speculate whether the behavioral sensitization induced by cannabinoids is a mechanism for the development of psychosis associated with chronic heavy cannabis use.

\section{Neurobiology of the Endocrine Effects of $\Delta-9$-THC}

Consistent with the literature, $\Delta-9$-THC increased plasma cortisol levels. $\Delta-9-$ THC increases ACTH and cortisol levels via $\mathrm{CB}-1$ receptor activation within the paraventricular nuclei, and either directly or indirectly (via other 
neurotransmitters) modulates $\mathrm{CRH}$ secretion (reviewed in Murphy et al, 1998). $\Delta$-9-THC produces an early and brief increase followed by a predominantly inhibitory effect on prolactin release (reviewed in Murphy et al, 1998), that is mediated by CB-1R activation of tuberoinfundibular (TIDA) DA neurons. The lack of a significant inhibitory $\Delta-9-$ THC effect of on plasma prolactin in this study may be explained by the brief period of observation.

\section{Limitations}

The possibility that some of the results observed could be attributed to alcohol effects cannot be ruled out completely. However, this seems unlikely since (1) alcohol was undetectable in blood; (2) subjects did not report behavioral effects consistent with the alcohol; and (3) in a limited number of subjects who participated in other studies, cognitive test performance on the placebo THC test day (ethanol vehicle) was not different to their performance on the placebo condition (saline) of other studies that they participated in. Finally, other studies using alcohol vehicle did not report any interactions between alcohol and $\Delta-9$ THC (Agurell et al, 1986; Lindgren et al, 1981; Ohlsson et al, 1980a).

The elimination half-life of $\Delta-9$-THC has been reported to vary from $18 \mathrm{~h}$ to 4.3 days (Hunt and Jones, 1980; Johansson et al, 1989; Kelly, 1992; Sadler et al, 1984; Wall et al, 1976, 1983; Wall and Perez-Reyes, 1981). The mean interval between each test day was 10 days. It is possible that a test session could have been under the influence of a previous session/s. However, the absence of detectable-9-THC in both urine and plasma samples at the baseline timepoint of each test day, and (2) the lack of any order effect in the statistical analysis, do not support a carryover effect from one test session to another. Further, other recent studies (Curran et al, 2002) (Fant et al, 1998) suggest that deficits in performance on sensitive tests of cognition produced by $\Delta$ 9-THC do not persist beyond 24-48 h.

Several limitations of this study might compromise the generalizability of the findings to the risks of cannabis use. Subjects generally reported $\Delta-9-\mathrm{THC}$ effects as dissimilar to their previous experience with cannabis. First, unlike the naturalistic setting, subjects were unable to 'titrate' the effects by controlling the dose or rate of administration. Second, the effects of cannabis are a composite of several (up to 80) cannabinoid compounds, terpenoids, and flavonoids that may modulate $\Delta$-9-THC (Hollister, 1988) effects and have 'entourage' effects (Mechoulam and BenShabat, 1999; Russo and McPartland, 2003). Cannabidiol (CBD), a major component of cannabis, has been shown to be a very low affinity, weak antagonist of CB-1R (Petitet et al, 1998). CBD and $\Delta$-9-THC may have pharmacokinetic and pharmacodynamic interactions. Thus, CBD may offset some $\Delta-9$-THC effects by its anxiolytic effects (Guimaraes et al, 1994; Zuardi et al, 1982), antipsychotic-like effects (Zuardi et al, 1995; Zuardi et al, 1991) and may block the conversion of $\Delta-9$-THC to the more psychoactive 11hydroxy-THC (Bornheim et al, 1995). However, the CBD content of cannabis varies greatly and some samples of cannabis have been reported to be devoid of CBD (Pitts et al, 1992). Fourth, the route of administration (intravenous) and rate of administration ( $2 \mathrm{~min})$ in this study is not socially relevant and may have resulted in a faster delivery and higher levels of $\Delta-9$-THC than what is typically achieved by recreational users. However, peak $\Delta$-9-THC plasma concentrations with the $2.5 \mathrm{mg}$ dose $(82 \pm 87.4 \mathrm{lng} /$ dl) and $5 \mathrm{mg}(119.2 \pm 166.5 \mathrm{ng} / \mathrm{dl})$ were within the range of levels achieved by ad libitum smoking of a standard NIDA cigarette $(70-163 \mathrm{ng} / \mathrm{ml})$ containing $1-2.5 \%$ THC (16$34 \mathrm{mg}$ ) (Heishman et al, 1990; Lindgren et al, 1981; Ohlsson et al, 1980a). Of note is that the $\Delta-9$-THC content of cannabis has increased (ElSohly et al, 2000) probably as a result of the cloning of high yield cannabis plants and advanced cultivation techniques. The average cannabis joint from the 1960s and 1970s contained about $10 \mathrm{mg}$ of THC. In contrast, cannabis joints from the current era made out of skunkweed, netherweed, and other potent subspecies of cannabis sativa may be 10-20 times more potent (Gold, 1991; Solowij, 1998; WHO, 1997).

Finally, cannabis dependent individuals who might 'benefit' from cannabis were excluded from this study and individuals with negative responses to cannabis either did not volunteer or were excluded. Thus, this study may not represent individuals who have either the most positive or negative responses to cannabis.

In conclusion, $\Delta-9$-THC produced a range of transient behavioral and cognitive effects in psychiatrically healthy individuals similar to those seen in schizophrenia and other endogenous psychoses. The findings of this study have implications for the toxicity of cannabinoid compounds and the pathophysiology of psychotic disorders.

\section{ACKNOWLEDGEMENTS}

We acknowledge support from the Department of Veterans Affairs (Schizophrenia Biological Research Center, Alcohol Research Center, National Center for PTSD and Merit Review Program (JK); National Institute of Alcohol Abuse and Alcoholism (KO2 AA 00261-04 to JK); (3) National Institute of Mental Health (RO1 MH61019-02 to DCD) (P50 MH44866-15 to JK); (4) National Institute of Drug Abuse ${ }^{\circledR} 1$ DA12382-01 to DCD); (5) Stanley Foundation (DCD); and (6) Donaghue Foundation (DCD). We also thank the Angelina Genovese (RN), Elizabeth O'Donnell (RN), Robert Sturwold (RPh), and Willy Ford of the Biological Studies Unit of the VA Connecticut Healthcare System, West Haven, CT.

\section{REFERENCES}

Acquas E, Pisanu A, Marrocu P, Di Chiara G (2000). Cannabinoid $\mathrm{CB}(1)$ receptor agonists increase rat cortical and hippocampal acetylcholine release in vivo. Eur J Pharmacol 401: 179-185.

Acquas E, Pisanu A, Marrocu P, Goldberg SR, Di Chiara G (2001). Delta9-tetrahydrocannabinol enhances cortical hippocampal acetylcholine release in vivo: a microdialysis study. Eur J Pharmacol 419: 155-161.

Adler CM, Goldberg TE, Malhotra AK, Pickar D, Breier A (1998). Effects of ketamine on thought disorder, working memory, and semantic memory in healthy volunteers. Biol Psychiatry 43: 811-816.

Agurell S, Halldin M, Lindgren JE, Ohlsson A, Widman M, Gillespie $\mathrm{H}$ et al (1986). Pharmacokinetics metabolism of delta 1tetrahydrocannabinol other cannabinoids with emphasis on man. Pharmacol Rev 38: 21-43. 
Andreasson S, Allebeck P, Engstrom A, Rydberg U (1987). Cannabis schizophrenia. A longitudinal study of Swedish conscripts. Lancet 2: 1483-1486.

Andreasson S, Allebeck P, Engstrom A, Rydberg U (1988). Cannabis schizophrenia. Lancet 1: 1000-1001.

Andreasson S, Allebeck P, Rydberg U (1989). Schizophrenia in users nonusers of cannabis. A longitudinal study in Stockholm County. Acta Psychiatr Scand 79: 505-510.

Angrist B, Sathananthan G, Wilk S, Gershon S (1974). Amphetamine psychosis: behavioral biochemical aspects. J Psychiatr Res 11: 13-23.

Arseneault L, Cannon M, Poulton R, Murray R, Caspi A, Moffitt TE (2002). Cannabis use in adolescence risk for adult psychosis: longitudinal prospective study. BMJ 325: 1212-1213.

Auclair N, Otani S, Soubrie P, Crepel F (2000). Cannabinoids modulate synaptic strength plasticity at glutamatergic synapses of rat prefrontal cortex pyramidal neurons. J Neurophysiol 83: 3287-3293.

Azorlosa JL, Heishman SJ, Stitzer ML, Mahaffey JM (1992). Marijuana smoking: effect of varying delta 9-tetrahydrocannabinol content number of puffs. J Pharmacol Exp Ther 261: 114-122.

Belger A, Puce A, Krystal JH, Gore JC, Goldman-Rakic P, McCarthy $\mathrm{G}$ (1998). Dissociation of mnemonic perceptual processes during spatial nonspatial working memory using fMRI. Hum Brain Mapping 6: 14-32.

Belmore SM, Miller LL (1980). Levels of processing acute effects of marijuana on memory. Pharmacol Biochem Behav 13: 199-203.

Belue RC, Howlett AC, Westlake TM, Hutchings DE (1995). The ontogeny of cannabinoid receptors in the brain of postnatal aging rats. Neurotoxicol Teratol 17: 25-30.

Beringer KVBW, Marx H (1932). des Haschischrausches (Clinical study on effects of hashish). Der Nervenarzt Berlin 337-350.

Bohme GA, Laville M, Ledent C, Parmentier M, Imperato A (2000). Enhanced long-term potentiation in mice lacking cannabinoid CB1 receptors. Neuroscience 95: 5-7.

Borkowski JG, Benton AL, Spreen O (1967). Word fluency and brain damage. Neuropsychologia 5: 135-140.

Bornheim LM, Kim KY, Li J, Perotti BY, Benet LZ (1995). Effect of cannabidiol pretreatment on the kinetics of tetrahydrocannabinol metabolites in mouse brain. Drug Metab Dispos 23: 825-831.

Brandt J, Corwin J, Krafft L (1992). Is verbal recognition memory really different in Huntington's Alzheimer's disease. J Clin Exp Neuropsychol 14: 773-784.

Bremner JD, Krystal JH, Putnam FW, Southwick SM, Marmar C, Charney DS et al (1998). Measurement of dissociative states with the Clinician-Administered Dissociative States Scale (CADSS). J Traumat Stress 11: 125-136.

Brunner E, Domhof S, Langer F (2002). Nonparametric Analysis of Longitudinal Data in Factorial Experiments. John Wiley and Sons: New York, NY.

Bylsma FW, Rebok GW, Brandt J (1991). Long-term retention of implicit learning in Huntington's disease. Neuropsychologia 29: 1213-1221.

Cadoni C, Pisanu A, Solinas M, Acquas E, Di Chiara G (2001). Behavioural sensitization after repeated exposure to Delta 9-tetrahydrocannabinol cross-sensitization with morphine. Psychopharmacology 158: 259-266.

Carta G, Nava F, Gessa GL (1998). Inhibition of hippocampal acetylcholine release after acute repeated Delta9-tetrahydrocannabinol in rats. Brain Res 809: 1-4.

Chait LD, Zacny JP (1992). Reinforcing subjective effects of oral delta 9-THC smoked marijuana in humans. Psychopharmacology 107: 255-262.

Chen J, Paredes W, Lowinson JH, Gardner EL (1990a). Delta 9tetrahydrocannabinol enhances presynaptic dopamine efflux in medial prefrontal cortex. Eur J Pharmacol 190: 259-262.
Chen JP, Paredes W, Li J, Smith D, Lowinson J, Gardner EL (1990b). Delta 9-tetrahydrocannabinol produces naloxoneblockable enhancement of presynaptic basal dopamine efflux in nucleus accumbens of conscious freely-moving rats as measured by intracerebral microdialysis. Psychopharmacology 102: $156-162$.

Chen JP, Paredes W, Lowinson JH, Gardner EL (1991). Strainspecific facilitation of dopamine efflux by delta 9-tetrahydrocannabinol in the nucleus accumbens of rat: an in vivo microdialysis study. Neurosci Lett 129: 136-180.

Cocchetto DM, Owens SM, Perez-Reyes M, DiGuiseppi S, Miller LL (1981). Relationship between plasma delta-9-tetrahydrocannabinol concentration pharmacologic effects in man. Psychopharmacology 75: 158-164.

Collins DR, Pertwee RG, Davies SN (1994). The action of synthetic cannabinoids on the induction of long-term potentiation in the rat hippocampal slice. Eur J Pharmacol 259: R7-R8.

Collins DR, Pertwee RG, Davies SN (1995). Prevention by the cannabinoid antagonist, SR141716A, of cannabinoid-mediated blockade of long-term potentiation in the rat hippocampal slice. Br J Pharmacol 115: 869-870.

Compton DR, Johnson MR, Melvin LS, Martin BR (1992). Pharmacological profile of a series of bicyclic cannabinoid analogs: classification as cannabimimetic agents. J Pharmacol Exp Ther 260: 201-209.

Cone EJ, Huestis MA (1993). Relating blood concentrations of tetrahydrocannabinol metabolites to pharmacologic effects time of marijuana usage. Ther Drug Monit 15: 527-532.

Corkin S, Milner B, Rasmussen T (1964). Effects of different cortical excisions on sensory thresholds in man. Trans Am Neurol Assoc 89: 112-116.

Curran HV, Brignell C, Fletcher S, Middleton P, Henry J (2002). Cognitive subjective dose-response effects of acute oral Delta 9tetrahydrocannabinol (THC) in infrequent cannabis users. Psychopharmacology 164: 61-70.

Dean B, Sundram S, Bradbury R, Scarr E, Copolov D (2001). Studies on $[3 \mathrm{H}] \mathrm{CP}-55940$ binding in the human central nervous system: regional specific changes in density of cannabinoid-1 receptors associated with schizophrenia and cannabis use. Neuroscience 103: 9-15.

Diana M, Melis M, Gessa GL (1998). Increase in meso-prefrontal dopaminergic activity after stimulation of $\mathrm{CB} 1$ receptors by cannabinoids. Eur J Neurosci 10: 2825-2830.

Duncan GE, Sheitman BB, Lieberman JA (1999). An integrated view of pathophysiological models of schizophrenia. Brain Res Brain Res Rev 29: 250-264.

Egertova M, Elphick MR (2000). Localisation of cannabinoid receptors in the rat brain using antibodies to the intracellular C-terminal tail of CB. J Comp Neurol 422: 159-171.

Egertova M, Giang DK, Cravatt BF, Elphick MR (1998). A new perspective on cannabinoid signalling: complementary localization of fatty acid amide hydrolase the CB1 receptor in rat brain. Proc Roy Soc London B Biol Sci 265: 2081-2085.

Ellison G (1994). Stimulant-induced psychosis, the dopamine theory of schizophrenia, the habenula. Brain Res Brain Res Rev 19: $223-239$.

Elphick MR, Egertova M (2001). The neurobiology evolution of cannabinoid signaling. Philos Trans Roy Soc London, Ser B 356: 381-408.

ElSohly MA, Ross SA, Mehmedic Z, Arafat R, Yi B, Banahan III BF (2000). Potency trends of delta9-THC other cannabinoids in confiscated marijuana from 1980-1997. J Forensic Sci 45: 24-30.

Emrich HM, Leweke FM, Schneider U (1997). Towards a cannabinoid hypothesis of schizophrenia: cognitive impairments due to dysregulation of the endogenous cannabinoid system. Pharmacol Biochem Behav 56: 803-807. 
Fant RV, Heishman SJ, Bunker EB, Pickworth WB (1998). Acute residual effects of marijuana in humans. Pharmacol Biochem Behav 60: 777-784.

French ED, Dillon K, Wu X (1997). Cannabinoids excite dopamine neurons in the ventral tegmentum substantia nigra. Neuroreport 8: $649-652$

French ED (1997). delta9-Tetrahydrocannabinol excites rat VTA dopamine neurons through activation of cannabinoid CB1 but not opioid receptors. Neurosci Lett 226: 159-162.

Freund TF, Katona I, Piomelli D (2003). Role of endogenous cannabinoids in synaptic signaling. Physiol Rev 83: 1017-1066.

Gerard CM, Mollereau C, Vassart G, Parmentier M (1991). Molecular cloning of a human cannabinoid receptor which is also expressed in testis. Biochem J 279: 129-134.

Gessa GL, Casu MA, Carta G, SMascia M (1998). Cannabinoids decrease acetylcholine release in the medial-prefrontal cortex hippocampus reversal by SR 141716A. Eur J Pharmacol 355: 119124.

Gessa GL, Mascia MS, Casu MA, Carta G (1997). Inhibition of hippocampal acetylcholine release by cannabinoids: reversal by SR 141716A. Eur J Pharmacol 327: R1-R2.

Glass M, Dragunow M, Faull RL (1997). Cannabinoid receptors in the human brain: a detailed anatomical quantitative autoradiographic study in the fetal, neonatal adult human brain. Neuroscience 77: 299-318.

Gold MS (1991). Marijuana In: Miller eNS (ed). Comprehensive Handbook of Alcohol Drug Addiction. Marcel Decker: New York. pp 353-376.

Gordon M (1986). Microprocessor-based assessment of attention deficit disorders (ADD). Psychopharmacol Bull 22: 288-290.

Gorriti MA, Rodriguez de Fonseca F, Navarro M, Palomo T (1999). Chronic (-)-delta9-tetrahydrocannabinol treatment induces sensitization to the psychomotor effects of amphetamine in rats. Eur J Pharmacol 365: 133-142.

Guimaraes FS, de Aguiar JC, Mechoulam R, Breuer A (1994. Anxiolytic effect of cannabidiol derivatives in the elevated plusmaze. Gen Pharmacol 25: 161-164.

Haertzen CA (1965). Addiction Research Center Inventory (ARCI): development of a general drug estimation scale. J Nerv Ment Dis 141: $300-307$.

Haertzen CA (1966). Development of scales based on patterns of drug effects using the addiction Research Center Inventory (ARCI). Psychol Rep 18: 163-194.

Hajos N, Katona I, Naiem SS, MacKie K, Ledent C, Mody I et al (2000). Cannabinoids inhibit hippocampal GABAergic transmission network oscillations. Eur J Neurosci 12: 3239-3249.

Hart CL, van Gorp W, Haney M, Foltin RW, Fischman MW (2001). Effects of acute smoked marijuana on complex cognitive performance. Neuropsychopharmacology 25: 757-765.

Heishman SJ, Arasteh K, Stitzer ML (1997). Comparative effects of alcohol marijuana on mood, memory, and performance. Pharmacol Biochem Behav 58: 93-101.

Heishman SJ, Huestis MA, Henningfield JE, Cone EJ (1990). Acute residual effects of marijuana: profiles of plasma THC levels, physiological subjective, and performance measures. Pharmacol Biochem Behav 37: 561-565.

Herkenham M, Lynn AB, Johnson MR, Melvin LS, de Costa BR, Rice KC (1991. Characterization localization of cannabinoid receptors in rat brain: a quantitative in vitro autoradiographic study. J Neurosci 11: 563-583.

Herkenham M, Lynn AB, Little MD, Johnson MR, Melvin LS, de Costa BR et al (1990). Cannabinoid receptor localization in brain. Proc Natl Acad Sci USA 87: 1932-1936.

Hoffman AF, Lupica CR (2000). Mechanisms of cannabinoid inhibition of GABA(A) synaptic transmission in the hippocampus. J Neurosci 20: 2470-2479.

Hollister LE (1988. Cannabis-1988. Acta Psychiatr Scand Suppl 345: $108-118$.
Hooker WD, Jones RT (1987). Increased susceptibility to memory intrusions the Stroop interference effect during acute marijuana intoxication. Psychopharmacology 91: 20-24.

Howlett AC, Barth F, Bonner TI, Cabral G, Casellas P, Devane WA et al (2002). International Union of Pharmacology. XXVII. Classification of cannabinoid receptors. Pharmacol Rev 54: 161202.

Huestis MA, Henningfield JE, Cone EJ (1992). Blood cannabinoids. I. Absorption of THC formation of 11-OH-THC THCCOOH during after smoking marijuana. J Anal Toxicol 16: 276-282.

Hunt CA, Jones RT (1980). Tolerance disposition of tetrahydrocannabinol in man. J Pharmacol Exp Ther 215: 35-44.

Jentsch JD, Andrusiak E, Tran A, Bowers Jr MB, Roth RH (1997). Delta 9-tetrahydrocannabinol increases prefrontal cortical catecholaminergic utilization impairs spatial working memory in the rat: blockade of dopaminergic effects with HA966. Neuropsychopharmacology 16: 426-432.

Johansson E, Noren K, Sjovall J, Halldin MM (1989). Determination of delta 1-tetrahydrocannabinol in human fat biopsies from marihuana users by gas chromatography-mass spectrometry. Biomed Chromatogr 3: 35-38.

Johns A (2001). Psychiatric effects of cannabis. Br J Psychiatry 178: $116-122$.

Jones RT (1971). Marihuana-induced 'high': influence of expectation, setting and previous drug experience. Pharmacol Rev 23: 359-369.

Katona I, Sperlagh B, Sik A, Kafalvi A, Vizi ES, Mackie K et al (1999a). Presynaptically located CB1 cannabinoid receptors regulate GABA release from axon terminals of specific hippocampal interneurons. J Neurosci 19: 4544-4558.

Katona I, Sperlagh B, Sik A, Kafalvi A, Vizi ES, Mackie K et al (1999b). Presynaptically located CB1 cannabinoid receptors regulate GABA release from axon terminals of specific hippocampal interneurons. J Neurosci 19: 4544-4558.

Katona I, Sperlagh B, Magloczky Z, Santha E, Kofalvi A, Czirjak S et al (2000). GABAergic interneurons are the targets of cannabinoid actions in the human hippocampus. Neuroscience 100: 797-804.

Kay SR, Opler LA, Lindenmayer JP (1989). The Positive Negative Syndrome Scale (PANSS): rationale and standardisation. $\mathrm{Br} J$ Psychiatry Suppl 59-67.

Kelly PJ, Rubino T (1992). Metabolism of tetrahydrocannabinol in frequent infrequent marijuana users. J Anal Toxicol 16: 28-235.

Krystal JH, Karper LP, Seibyl JP, Freeman GK, Delaney R, Bremner JD et al (1994). Subanesthetic effects of the noncompetitive NMDA antagonist, ketamine, and in humans. Psychotomimetic perceptual, cognitive, and neuroendocrine responses. Arch Gen Psychiatry 51: 199-214.

Lamarque S, Taghzouti K, Simon H (2001). Chronic treatment with Delta(9)-tetrahydrocannabinol enhances the locomotor response to amphetamine and heroin. Implications for vulnerability to drug addiction. Neuropharmacology 41: 118-129.

Laruelle M (2000). The role of endogenous sensitization in the pathophysiology of schizophrenia: implications from recent brain imaging studies. Brain Res Brain Res Rev 31: 371-384.

Lemberger L, Axelrod J, Kopin IJ (1971). Metabolism disposition of delta-9-tetrahydrocannabinol in man. Pharmacol Rev 23: 371-380.

Leweke FM, Giuffrida A, Wurster U, Emrich HM, Piomelli D (1999a). Elevated endogenous cannabinoids in schizophrenia. Neuroreport 10: 1665-1669.

Leweke FM, Schneider U, Radwan M, Schmidt E, Emrich HM (2000). Different effects of nabilone cannabidiol on binocular depth inversion in man. Pharmacol Biochem Behav 66: 175-181.

Leweke FM, Schneider U, Thies M, Munte TF, Emrich HM (1999b). Effects of synthetic delta9-tetrahydrocannabinol on binocular depth inversion of natural artificial objects in man. Psychopharmacology (Berlin) 142: 230-235. 
Lichtman AH, Varvel SA, Martin BR (2002). Endocannabinoids in cognition and dependence. Prostaglandins Leukot Essent Fatty Acids 66: 269-285.

Lieberman JA, Kane JM, Alvir J (1987). Provocative tests with psychostimulant drugs in schizophrenia. Psychopharmacology 91: 415-433.

Lindgren JE, Ohlsson A, Agurell S, Hollister L, Gillespie H (1981). Clinical effects plasma levels of delta 9-tetrahydrocannabinol (delta 9-THC) in heavy and light users of cannabis. Psychopharmacology 74: 208-212.

Malhotra AK, Pinals DA, Weingartner H, Sirocco K, Missar CD, Pickar D et al (1996). NMDA receptor function human cognition: the effects of ketamine in healthy volunteers. Neuropsychopharmacology 14: 301-307.

Marks DF, MacAvoy MG (1989). Divided attention performance in cannabis users non-users following alcohol cannabis separately in combination. Psychopharmacology 99: 397-401.

Matsuda LA, Lolait SJ, Brownstein MJ, Young AC, Bonner TI (1990). Structure of a cannabinoid receptor functional expression of the cloned cDNA. Nature 346: 561-564.

McGuire PK, Jones P, Harvey I, Williams M, McGuffin P, Murray RM (1995). Morbid risk of schizophrenia for relatives of patients with cannabis-associated psychosis. Schizophr Res 15: 277-281.

Mechoulam R, Ben-Shabat S (1999). From gan-zi-gun-nu to anandamide 2-arachidonoylglycerol: the ongoing story of cannabis. Nat Product Rep 16: 131-143.

Melis M, Gessa GL, Diana M (2000). Different mechanisms for dopaminergic excitation induced by opiates cannabinoids in the rat midbrain. Prog Neuro-Psychopharmacol Biol Psychiatry 24: 993-1006

Miller LL, Branconnier RJ (1983). Cannabis: effects on memory the cholinergic limbic system. Psychol Bull 93: 441-456.

Miller LL, McFarland D, Cornett TL, Brightwell D (1977). Marijuana memory impairment: effect on free recall recognition memory. Pharmacol Biochem Behav 7: 99-103.

Misner DL, Sullivan JM (1999). Mechanism of cannabinoid effects on long-term potentiation depression in hippocampal CA1 neurons. J Neurosci 19: 6795-6805.

Miyamoto A, Yamamoto T, Ohno M, Watanabe S, Tanaka H, Morimoto $S$ et al (1996). Roles of dopamine D1 receptors in delta 9-tetrahydrocannabinol-induced expression of Fos protein in the rat brain. Brain Res 710: 234-240.

Miyamoto A, Yamamoto T, Watanabe S (1995). Effect of repeated administration of delta 9-tetrahydrocannabinol on delayed matching-to-sample performance in rats. Neurosci Lett 201: 139-142.

Moreau J (1973) In: Peters NGH (ed). Hashish Mental Illness. Raven Press: New York. pp 245.

Moreau de Tours J (1973). Sobre el hachisch y la alienacion mental. Actas Luso-Espanolas Neurol Psiquiatr Cienc Afines 1: 477-484.

Murphy LL, Munoz RM, Adrian BA, Villanua MA (1998). Function of cannabinoid receptors in the neuroendocrine regulation of hormone secretion. Neurobiol Dis 5: 432-446.

Muschamp JW, Siviy SM (2002). Behavioral sensitization to amphetamine follows chronic administration of the CB1 agonist WIN 55,212-2 in Lewis rats. Pharmacol Biochem Behav 73: $835-842$.

Nava F, Carta G, Colombo G, Gessa GL (2001). Effects of chronic $\operatorname{Delta}(9)$-tetrahydrocannabinol treatment on hippocampal extracellular acetylcholine concentration and alternation performance in the T-maze. Neuropharmacology 41: 392-399.

Nowicky AV, Teyler TJ, Vardaris RM (1987). The modulation of long-term potentiation by delta-9-tetrahydrocannabinol in the rat hippocampus, in vitro. Brain Res Bull 19: 663-672.

Ohlsson A, Lindgren JE, Wahlen A, Agurell S, Hollister LE, Gillespie HK (1980a). Plasma delta-9 tetrahydrocannabinol concentrations clinical effects after oral intravenous administration smoking. Clin Pharmacol Ther 28: 409-416.
Ohlsson A, Widman M, Carlsson S, Ryman T, Strid C (1980b). Plasma brain levels of delta 6-THC seven monooxygenated metabolites correlated to the cataleptic effect in the mouse. Acta Pharmacol Toxicol 47: 308-317.

Patel S, Hillard CJ (2003). Cannabinoid-induced Fos expression within A10 dopaminergic neurons. Brain Res 963: 15-25.

Pertwee RG (1999a). Cannabis cannabinoids: pharmacology and rationale for clinical use. Forsch Komplementarmed 6(Suppl 3): $12-15$.

Pertwee RG (1999b). Pharmacology of cannabinoid receptor ligands. Curr Med Chem 6: 635-664.

Petitet F, Jeantaud B, Reibaud M, Imperato A, Dubroeucq MC (1998). Complex pharmacology of natural cannabinoids: evidence for partial agonist activity of delta9-tetrahydrocannabinol and antagonist activity of cannabidiol on rat brain cannabinoid receptors. Life Sci 63: L1-L6.

Pistis M, Muntoni AL, Pillolla G, Gessa GL (2002). Cannabinoids inhibit excitatory inputs to neurons in the shell of the nucleus accumbens: an in vivo electrophysiological study. Eur J Neurosci 15: $1795-1802$.

Pistis M, Porcu G, Melis M, Diana M, Gessa GL (2001). Effects of cannabinoids on prefrontal neuronal responses to ventral tegmental area stimulation. Eur J Neurosci 14: 96-102.

Pitts JE, Neal JD, Gough TA (1992). Some features of Cannabis plants grown in the United Kingdom from seeds of known origin. J Pharm Pharmacol 44: 947-951.

Porcella A, Gessa GL, Pani L (1998). Delta9-tetrahydrocannabinol increases sequence-specific AP-1 DNA-binding activity Fos-related antigens in the rat brain. Eur J Neurosci 10: 1743-1751.

Rubino T, Vigano D, Massi P, Parolaro D (2001). The psychoactive ingredient of marijuana induces behavioural sensitization. Eur J Neurosci 14: 884-886.

Rubino T, Vigano D, Massi P, Parolaro D (2003). Cellular mechanisms of Delta 9-tetrahydrocannabinol behavioural sensitization. Eur J Neurosci 17: 325-330.

Russo EB, McPartland JM (2003). Cannabis is more than simply delta(9)-tetrahydrocannabinol [comment]. Psychopharmacology 165: 431-432 author reply 433-434.

Sadler B, Wall ME, Perez-Reyes M (1984). The pharmacokinetics of delta-9-tetrahydrocannabinol in after simultaneous intravenous oral administration In: The Cannabinoids: Chemical Pharmacologic Therapeutic Aspects. Acadamic Press Inc.: Orlando, Fla. pp 227-238.

Schneider U, Leweke FM, Mueller-Vahl KR, Emrich HM (1998). Cannabinoid/anandamide system schizophrenia: is there evidence for association? Pharmacopsychiatry 31: 110-113.

Shaw LM, Edling-Owens J, Mattes R (1991). Ultrasensitive measurement of delta-9-tetrahydrocannabinol with a high energy dynode detector electron-capture negative chemical-ionization mass spectrometry. Clin Chem 37: 2062-2068.

Siomopoulos V (1975). Amphetamine psychosis: overview a hypothesis. Dis Nerv System 36: 336-339.

Snyder SH (1973). Amphetamine psychosis: a 'model' schizophrenia mediated by catecholamines. Am J Psychiatry 130: 61-67.

Solowij N (1998). Cannabis Cognitive Functioning. Cambridge University Press: Cambridge.

Solowij N, Michie PT, Fox AM (1991). Effects of long-term cannabis use on selective attention: an event-related potential study. Pharmacol Biochem Behav 40: 683-688.

Spencer KM, Nestor PG, Niznikiewicz MA, Salisbury DF, Shenton ME, McCarley RW (2003). Abnormal neural synchrony in schizophrenia. J Neurosci 23: 7407-7411.

Spitzer RL, Davies M, Barkley RA (1990). The DSM-III-R field trial of disruptive behavior disorders. J Am Acad Child Adolesc Psychiatry 29: 690-697. 
Sullivan JM (1999). Mechanisms of cannabinoid-receptormediated inhibition of synaptic transmission in cultured hippocampal pyramidal neurons. J Neurophysiol 82: 1286-1294.

Tanda G, Pontieri FE, Di Chiara G (1997). Cannabinoid heroin activation of mesolimbic dopamine transmission by a common mul opioid receptor mechanism (comment). Science 276: 2048-2050.

Terranova JP, Michaud JC, Le Fur G, Soubrie P (1995). Inhibition of long-term potentiation in rat hippocampal slices by anandamide and WIN55212-2: reversal by SR141716 A, a selective antagonist of CB1 cannabinoid receptors. Naunyn Schmiedebergs Arch Pharmacol 352: 576-579.

Tsou K, Mackie K, Sanudo-Pena MC, Walker JM (1999). Cannabinoid CB1 receptors are localized primarily on cholecystokinin-containing GABAergic interneurons in the rat hippocampal formation. Neuroscience 93: 969-975.

Ujike H, Takaki M, Nakata K, Tanaka Y, Takeda T, Kodama M et al (2002). CNR1 central cannabinoid receptor gene associated with susceptibility to hebephrenic schizophrenia. Mol Psychiatry 7: 515-518.

van Os J, Bak M, Hanssen M, Bijl RV, de Graaf R, Verdoux $\mathrm{H}$ (2002). Cannabis use and psychosis: a longitudinal populationbased study. Am J Epidemiol 156: 319-327.

Volkow ND, Gillespie H, Mullani N, Tancredi L, Grant C, Valentine A et al (1996). Brain glucose metabolism in chronic marijuana users at baseline and during marijuana intoxication. Psychiatry Res 67: 29-38.

Volkow ND, Fowler JS, Wolf AP, Gillespi H (1991). Metabolic studies of drugs of abuse. NIDA Research Monograph 105: 47-53.

Vollenweider FX, Vollenweider-Scherpenhuyzen MF, Babler A, Vogel H, Hell D (1998). Psilocybin induces schizophrenia-like psychosis in humans via a serotonin-2 agonist action. Neuroreport 9: 3897-3902.

Vollenweider FX, Vontobel P, Oye I, Hell D, Leenders KL (2000). Effects of $(S)$-ketamine on striatal dopamine: a (11C) raclopride
PET study of a model psychosis in humans. J Psychiatric Res 34: 35-43.

Wall ME, Perez-Reyes M (1981). The metabolism of delta 9tetrahydrocannabinol and related cannabinoids in man. J Clin Pharmacol 21: 178S-189S.

Wall ME, Sadler BM, Brine D, Taylor H, Perez-Reyes M (1983). Metabolism disposition and kinetics of delta-9-tetrahydrocannabinol in men and women. Clin Pharmacol Ther 34: 352-363.

Wall ME, Brine DR, Perez-Reyes M (1976). Metabolism of cannabinoids in man In: Braude MC, Szara S (eds). Pharmacology of Marihuana Vol 1, pp 536.

World Health Organization (WHO) (1997). Programme on substance abuse. Cannabis: a health perspective and research agenda.

Wilson RI, Nicoll RA (2002). Endocannabinoid signaling in the brain. Science 296: 678-682.

Yui K, Goto K, Ikemoto S, Ishiguro T, Angrist B, Duncan GE et al. (1999). Neurobiological basis of relapse prediction in stimulantinduced psychosis and schizophrenia: the role of sensitization. Mol Psychiatry 4: 512-523.

Zammit S, Allebeck P, Andreasson S, Lundberg I, Lewis G (2002). Self reported cannabis use as a risk factor for schizophrenia in Swedish conscripts of 1969: historical cohort study. BMJ 325: 1199.

Zuardi AW, Morais SL, Guimaraes FS, Mechoulam R (1995). Antipsychotic effect of cannabidiol (letter). J Clin Psychiatry 56: 485-486.

Zuardi AW, Rodrigues JA, Cunha JM (1991). Effects of cannabidiol in animal models predictive of antipsychotic activity. Psychopharmacology 104: 260-264.

Zuardi AW, Shirakawa I, Finkelfarb E, Karniol IG (1982). Action of cannabidiol on the anxiety and other effects produced by delta 9-THC in normal subjects. Psychopharmacology 76: 245-250. 